\title{
Endogenous longevity and optimal tax progressivity ${ }^{\text {th }}$
}

\author{
Burkhard Heer ${ }^{\mathrm{a}, \mathrm{b}, *}$, Stefan Rohrbacher ${ }^{\mathrm{a}}$ \\ ${ }^{\text {a } U n i v e r s i t y ~ o f ~ A u g s b u r g, ~ D e p a r t m e n t ~ o f ~ E c o n o m i c s, ~ U n i v e r s i t a t s s t r a s s e ~ 16, ~} 86159$ Augsburg, Germany \\ ${ }^{\mathrm{b}}$ CESifo, Munich, Germany
}

\section{A R T I C L E I N F O}

\section{JEL classification:}

I14

J10

H21

H51

D31

\section{Keywords:}

Health and inequality

Demography

Second-best

Optimal taxation

Personal income distribution

Overlapping generations

\begin{abstract}
A B S T R A C T
We study the impact of endogenous longevity on optimal tax progressivity and inequality in an overlapping generations model with skill heterogeneity. Higher tax progressivity decreases both the longevity gap and net income inequality, but at the expense of lower average lifetime and income. We find that the welfare-maximizing income tax is less progressive in our model with endogenous longevity than in our model with exogenous longevity. In a highly stylized calibration of the US economy, we show that optimal tax progressivity is less than what prevails under the current US tax system. Our results are robust to the range of empirical labor supply elasticity and the assumptions of missing annuity markets and stochastic health. Our conclusion for the optimal progressivity of the US tax system can be altered by the adoption of a more egalitarian welfare function or by increases in prevailing levels of wage inequality.
\end{abstract}

\section{Introduction}

Many studies report large differences in longevity across socioeconomic characteristics such as income and education level (see, e.g., Cristia, 2009; Sorlie and Keller, 1995 and Pijoan-Mas and Ríos-Rull, 2014). Additionally, there is strong empirical evidence that medical expenditures increase longevity; Lantz et al. (1998), for example, report significant effects of income on mortality after controlling for various socioeconomic factors, while Martin et al. (2008) find that higher health expenditures reduce the mortality from cancer and circulatory disease. Moreover, Cremieux et al. (1999) show that health care spending decreases infant mortality and increases life expectancy, while Mays and Smith (2011) find a reduction in infant mortality and mortality related to heart disease, diabetes, and cancer through higher health expenditures.

The presence of endogenous longevity sheds new light on the importance of income redistribution by the government. Conventionally, economists argue in favor of income redistribution from rich to poor households because the latter are characterized by a higher marginal utility of consumption. If utility is concave in consumption, a redistribution of income increases average utility, ceteris paribus.

In the present study, we also analyze the role of income redistribution, emphasizing a new transmission channel of inequality. If longevity is endogenous and depends on the individual's income, a redistribution of income also helps to increase welfare by reducing the variance of longevity among individuals. Poorer households that benefit from higher transfers increase their savings and investment in health. As a consequence, they both work and live longer at the expense of the income-rich households that, in

\footnotetext{
We would like to thank Jeffrey Clemens and two anonymous referees for their helpful and constructive comments. We also thank Juergen Jung and Chung Tran for the provision of their data and estimates on the dynamics of age-dependent health capital. All remaining errors are ours.

* Corresponding author.

E-mail addresses: burkhard.heer@wiwi.uni-augsburg.de (B. Heer), stefan.rohrbacher@wiwi.uni-augsburg.de (S. Rohrbacher).
} 
turn, decrease their savings and health spending. Since the health production function is very likely to be concave in private health spending in developed countries (see, e.g., Hall and Jones, 2007 or Baltagi et al., 2012), we would expect a stronger gain in the longevity of households with low income than the corresponding loss in longevity among households with high income. Therefore, redistribution from high- to low-income households increases both average lifetime and, hence, utility in partial equilibrium.

In general equilibrium, there are many effects on aggregate income and savings that may counteract the two aforementioned positive partial-equilibrium effects that result from the concavity of the utility and health production function. Since high-income households are characterized by higher productivity than low-income households, the reduction in labor supply and savings among the former is quantitatively more significant than the respective increases among the latter. As a consequence, aggregate labor and savings might decline, meaning that aggregate income also decreases. Therefore, the general equilibrium is likely to reduce both the lifetime and utility of all households, which may even outweigh the positive partial equilibrium that stems from the redistribution to the poor. Therefore, the optimality of redistribution in the presence of endogenous longevity can only be studied in a generalequilibrium model.

In the present study, we analyze the optimal second-best policy when the government can only redistribute among individuals with the help of a progressive labor income tax. In our simple two-period overlapping generations (OLG) model, households are heterogeneous with respect to labor productivity. We distinguish two types of workers, skilled and unskilled. In the first period of life, households work and choose their labor supply. They save for old age and purchase private health services that determine their health and longevity during old age. In old age, the agents simply consume their savings. We calibrate the model with respect to the characteristics of the US economy. As our main result, we find that the argument for redistributing income with the help of progressive income taxes is undermined due to endogenous longevity. Our result is also shown to be robust to a variety of sensitivity analyses, including the application of empirically observed values for the Frisch labor supply elasticity or the elasticity of longevity with respect to individual health. Moreover, our result also holds in the absence of annuity markets or when private health expenditures can be deducted from taxable income.

This paper contributes to the literature on the optimal income tax progressivity in general equilibrium. In this literature, reducing inequality increases average utility due to the concavity of the utility function. In addition, these studies introduce idiosyncratic wage risk against which progressive taxes also provide social insurance in the absence of perfect insurance markets. As one of the earliest studies in this area, Ventura (1999) considers the revenue-neutral tax reform in which a flat-rate income tax replaces the progressive income tax in the US economy. He finds that, although income becomes more concentrated, average utility is increased because the lower distortions on labor supply and savings outweigh the detriments from higher inequality. Conesa and Krueger (2006) consider a similar model of the US economy but also derive the optimal US progressive income tax schedule consisting of a linear tax of $17.2 \%$ with a fixed deductions of $\$ 9,400$, which is much less progressive than the current US tax system. Krueger and Ludwig (2016) argue that the optimal progressivity of the income tax code might also be reduced in the presence of endogenous college education. ${ }^{1}$

In this case, redistribution should rely more heavily on education subsidies than on income transfers. If, as a consequence, more individuals attend college, the college wage premium falls in equilibrium, which constitutes a policy substitute for redistributive tax progressivity. Heathcote et al. (2017) develop a simple tractable model that combines all the channels mentioned above. In addition, they introduce a poverty trap constraint for low-income households that prevents them from investing in their skills. They find that optimal progressivity should be notably less than that in the current US tax system; in particular, the optimal average marginal tax rate should amount to $26 \%$, while it is equal to $34 \%$ in the US economy. However, they also find their results to be sensitive to the consideration of the endogenous provision of public goods, higher aversion to inequality, or larger constraints on skill investment. None of these studies, however, considers endogenous longevity.

In accordance with these studies, we find that the optimal income tax in our highly stylized model is less progressive than presently in the US economy and implies welfare gains equal to $0.19-0.44 \%$ of total consumption. ${ }^{2}$

A less progressive income tax creates winner and losers. While average welfare of the newborn is found to prevail at a progressivity index that is much lower than the present one in the US economy ( 0.0642 versus 0.137 with zero corresponding to a flat-rate tax), we find that unskilled worker will suffer from a low progression or even flat-rate income tax despite the overall positive general equilibrium effects. In addition, the education longevity gap, i.e. the difference in expected lifetime between the high- and lowskilled worker, increases by approximately 3 months if the tax progressivity decreases to its optimal level in our model. Evidently, our optimality result depends on the use of an egalitarian welfare function and can be overturned by the use of a Rawlsian welfare function. In addition, our result is found to be sensitive with respect to the (hourly) wage inequality in the economy. If inequality increases above the present US level, optimal tax progression might increase to the present level or even surpass it.

Our analysis also contributes to the literature on the redistribution of both income and health using either fiscal or health policies. We find that a tax policy that reduces net income inequality also reduces inequality in (expected) longevity and increases welfare of the low-income group; however, due to general equilibrium effects, average welfare is reduced. Jeske and Kitao (2009) find that US tax policy on health insurance is increasing income inequality because only those offered group insurance through their employer are subsidized. Jung and Tran (2016) consider the U.S. health care reform 2010 in the form of the Affordable Care Act (ACA) also

\footnotetext{
${ }^{1}$ In our model, differences in innate abilities and endogenous education are not considered, but rather assumed as exogenously given.

2 Different from the literature referenced in the previous paragraph, we consider a model with an extremely simplified demographic structure distinguishing only two cohorts, the young and the old. For this reason, we only imperfectly model life-cycle savings which may provide insurance against health risk and the risk of longevity. In light of our highly-stylized calibration of the US economy, we refrain from interpreting our results on the optimality of the present tax progressivity as a recommendation for US tax policy but rather as evidence that the results in the studies of Conesa and Krueger (2006) or Heathcote et al. (2017) are maintained and even strengthened in the presence of endogenous longevity.
} 
known as 'Obamacare'. As the main goal of this policy, the health coverage rate, especially among low-income groups, is targeted to increase. The Affordable Care Act is found to redistribute income both from low to high health risk types and from high to low income groups. Therefore, the redistribution of income and health resulting from the ACA are intertwined and work in the same direction as in our model. Different from our study, however, Jung and Tran (2016) only consider exogenous longevity.

Our paper is organized as follows. In Section 2, we present our OLG model with heterogeneous agents (skilled and unskilled). The model is calibrated with respect to the characteristics of the US economy in Section 3. In Section 4, we derive our main results that optimal income tax progressivity is lower in the presence of endogenous longevity and, in our highly stylized calibration of the US economy, below the present progressivity. The sensitivity of these results is examined in Section 5. Section 6 considers the redistributive role of health insurance and, therefore, introduces stochastic health into our model. Section 7 concludes the paper. Mathematical derivations and additional sensitivity analyses are relegated to the Appendix.

\section{Model}

We consider a standard two-period OLG model augmented by endogenous survival and progressive (labor) income taxation. Households are heterogeneous in their labor productivity during working life and their assets in old age. We distinguish two productivity types, unskilled $(L)$ and skilled $(H)$.

\subsection{Demographics}

Let $N_{t}$ denote the measure of young households in period $t$, which grows at the constant population growth rate $n$

$$
N_{t}=(1+n) N_{t-1} \text {. }
$$

In each generation, the shares of unskilled and skilled workers amount to $\phi$ and $1-\phi$, respectively.

\subsection{Households}

Households are heterogeneous in their labor productivity $e^{i}$ with $i \in\{L, H\}$. The unskilled and skilled productivity types are meant to capture differences in education and abilities $e^{L}<e^{H}$.

The gross labor income of a working household with productivity level $e^{i}$ in period $t, y_{t}^{i}$, is given by the product of its productivity $e^{i}$ and labor supply $l_{t}^{i}$ and the wage rate $w_{t}$ :

$$
y_{t}^{i}=e^{i} l_{t}^{i} w_{t} .
$$

To model a progressive tax system for labor income, we follow Holter et al., 2019 and define a household's total tax burden as

$$
T\left(y_{t}^{i}\right)=y_{t}^{i}-\theta_{0, t}\left(y_{t}^{i}\right)^{1-\theta_{1}},
$$

implying a marginal income tax of

$$
\tau\left(y_{t}^{i}\right)=1-\left(1-\theta_{1}\right) \theta_{0, t}\left(y_{t}^{i}\right)^{-\theta_{1}} .
$$

The parameter $\theta_{1}$ measures the (constant) degree of tax progressivity, while $\theta_{0, t}$ defines the tax level in period $t$. The tax system is progressive for $\theta_{1} \in(0,1)$, regressive for $\theta_{1}<0$ and linear for $\theta_{1}=0$. Net income $\hat{y}_{t}^{i}$ is presented by

$$
\hat{y}_{t}^{i}=\theta_{0, t}\left(y_{t}^{i}\right)^{1-\theta_{1}} \text {. }
$$

The health state of an individual with productivity level $e^{i}$ at the end of his or her first period, $h_{t}^{i}$, is endogenous and depends on private health expenditures $x_{t}^{i}$ and public health expenditures per capita $\eta_{t}:^{3}$

$$
h_{t}^{i}=\left(x_{t}^{i}\right)^{\gamma}\left(\eta_{t}\right)^{1-\gamma}
$$

where $\gamma$ describes the elasticity of the health state with respect to private health expenditures. In old age, the household does not invest privately in its health but only enjoys public health expenditures $\eta_{t} \cdot{ }^{4}$

The survival probabilities of households are endogenous and depend on the household's health status $h$. The survival probability $\psi(h)$ at the end of an individual's youth follows a strictly increasing (though bounded) function satisfying

$$
\psi(0)=\underline{\psi} \geq 0, \psi^{\prime}>0, \psi^{\prime \prime} \leq 1,
$$

\footnotetext{
${ }^{3}$ Fiorini (2010) presents empirical evidence that private and public health expenditures are substitutes in the health production function. In our sensitivity analysis in Appendix A.4, we consider a more general form of the health production function (CES function) but find our results to be robust to the degree of substitution elasticity.

${ }^{4}$ Since we are interested in the mechanism of endogenous longevity, we refrain from modeling the health expenditures of the elderly, e.g., on chronic and nonfatal diseases. Nevertheless, we consider the effects of a change in average longevity on aggregate public health expenditures.
} 
with $\psi$ describing the lower bound of the probability function. Following Chakraborty and Das (2005), we model the survival probability function as follows: ${ }^{5}$

$$
\psi\left(h_{t}^{i}\right)=\psi_{0}\left(h_{t}^{i}\right)^{\varepsilon}, \quad 0<\epsilon \leq 1
$$

A young household with productivity level $e^{i}$ maximizes expected lifetime utility $U$ in period $t$

$$
U\left(c_{t}^{i}, d_{t+1}^{i}, l_{t}^{i}, h_{t}^{i}\right)=u\left(c_{t}^{i}\right)+\beta \psi\left(h_{t}^{i}\right) u\left(d_{t+1}^{i}\right)-v\left(l_{t}^{i}\right),
$$

where $c_{t}^{i}$ and $d_{t+1}^{i}$ denote consumption at young and old age of a household with productivity $e^{i}$ in periods $t$ and $t+1$, respectively, and $\beta>0$ denotes the discount factor.

When young, households face a budget constraint equal to

$$
c_{t}^{i}+x_{t}^{i}+a_{t}^{i}=\hat{y}_{t}^{i}
$$

with $a_{t}^{i}$ describing savings.

The old household only receives income from savings. We assume perfect annuity markets without transaction costs. ${ }^{6}$ Consequently, consumption of an old household with productivity $e^{i}$ in period $t+1$ is described by ${ }^{7}$

$$
d_{t+1}^{i}=\frac{\left(1+r_{t+1}\right)}{\psi\left(h_{t}^{i}\right)} a_{t}^{i}
$$

The first-order conditions of the utility maximization problem with respect to $c_{t}^{i}, d_{t}^{i}, l_{t}^{i}$ and $x_{t}^{i}$ are given by

$$
\begin{aligned}
& \frac{v^{\prime}\left(l_{t}^{i}\right)}{u^{\prime}\left(c_{t}^{i}\right)}=\left(1-\theta_{1}\right) \frac{\hat{y}_{t}^{i}}{l_{t}^{i}}, \\
& u^{\prime}\left(c_{t}^{i}\right)=\beta\left(1+r_{t+1}\right) u^{\prime}\left(d_{t+1}^{i}\right), \\
& \psi^{\prime}\left(h_{t}^{i}\right) h^{\prime}\left(x_{t}^{i}\right) u\left(d_{t+1}^{i}\right)=\left(1+r_{t+1}\right) u^{\prime}\left(d_{t+1}^{i}\right),
\end{aligned}
$$

where (2.12a) describes the tradeoff between consumption and leisure, (2.12b) is the Euler equation and (2.12c) describes the tradeoff between the quantity of life (longevity) and quality of life (old-age consumption).

We follow Dalgaard and Strulik, 2014 and assume logarithmic instantaneous utility from consumption $u(c)$ (and analogous for $u(d))$ such that ${ }^{8}$

$$
u(c)=b+\ln c,
$$

where the constant term $b \geq 0$ ensures that utility from consumption always takes a positive value, as discussed by Hall and Jones (2007) and Dalgaard and Strulik, 2014. ${ }^{9}$ Disutility from labor $v(l)$ is specified as

$$
v(l)=v_{0} \frac{l^{1+\frac{1}{v_{1}}}}{1+\frac{1}{v_{1}}},
$$

where $v_{1}>0$ represents the Frisch elasticity of labor supply and $v_{0}>0$ measures the disutility level of work effort.

\subsection{Government}

The government uses the tax revenues from labor income to finance public consumption $G_{t}$ and public health expenditures $X_{t}^{p u b}$. The government budget balances in every period $t$ :

$$
\phi N_{t} T\left(y_{t}^{L}\right)+(1-\phi) N_{t} T\left(y_{t}^{H}\right)=G_{t}+X_{t}^{p u b}
$$

Total public health expenditures are equal to the sum of health expenditures on all young and old households:

$$
X_{t}^{p u b}=N_{t} \eta_{t}+N_{t-1}\left[\phi \psi\left(h_{t-1}^{L}\right)+(1-\phi) \psi\left(h_{t-1}^{H}\right)\right] \eta_{t} .
$$

\footnotetext{
${ }^{5}$ Bhattacharya and Qiao (2007) and Chakraborty (2004) also apply a survival probability function that is concave in health. Empirical evidence for this hypothesis is provided by Hall and Jones (2007) and Baltagi et al. (2012).

${ }^{6}$ We consider the absence of annuity markets in our sensitivity analysis in Section 5.

${ }^{7}$ Note our assumption that the financial intermediary can ascertain the health level of an individual with productivity $e^{i}$ in period $t, h_{t}^{i}$, without any transaction costs.

${ }^{8}$ Logarithmic utility finds empirical support from Chetty (2006), who presents estimates of the intertemporal elasticities of substitution (IES) close to 1 .

${ }^{9}$ If $c$ is sufficiently small, $u(c)<0$. Therefore, in the case of $b=0$, a household would be better off if not alive in the second period of life since utility from being dead is zero (see, e.g., Rosen, 1988).
} 


\subsection{Production}

Production $Y_{t}$ is characterized by constant returns to scale in aggregate capital $K_{t}$ and labor supply $L_{t}$ and specified as a CobbDouglas function:

$$
Y_{t}=A K_{t}^{\alpha} L_{t}^{1-\alpha},
$$

where $\alpha$ is the production elasticity of capital. Aggregate labor supply $L_{t}$ comprises skilled and unskilled labor supply:

$$
L_{t}=\left(\phi N_{t}\right) e^{L} l_{t}^{L}+\left((1-\phi) N_{t}\right) e^{H} l_{t}^{H} .
$$

Goods and factor markets are competitive such that input factors are rewarded with their marginal products:

$$
w_{t}=(1-\alpha) A L_{t}^{-\alpha} K_{t}^{\alpha}
$$

$$
r_{t}=\alpha A L_{t}^{1-\alpha} K_{t}^{\alpha-1}-\delta
$$

where $\delta$ denotes the depreciation rate.

\subsection{Competitive equilibrium}

Let $X_{t}, C_{t}$, and $I_{t}$ denote aggregate private health expenditures, aggregate consumption (of both the young and the old agents), and aggregate investment. To express the competitive equilibrium in terms of stationary variables, we need to divide all aggregate variables $\left\{Y_{t}, K_{t}, L_{t}, X_{t}^{p u b}, X_{t}, C_{t}, I_{t}\right\}$ by the number of young agents, $N_{t}$, and denote them by a tilde, e.g., $\tilde{Y} \equiv Y_{t} / N_{t}$.

Given the government policy $\left(\tilde{X}_{t}^{p u b}, \tilde{G}_{t}, \theta_{1}\right)_{t=0}^{\infty}$, the initial capital stock $\tilde{K}_{0}$ and the initial distribution of the health status among the young households, $\left(h_{0}^{L}, h_{0}^{H}\right)$, a stationary competitive equilibrium for our economy is a tax level $\theta_{0, t}$, factor prices $w_{t}$ and $r_{t}$, individual decision rules $c_{t}^{i}, d_{t+1}^{i}, x_{t}^{i}, a_{t}^{i}$, and $l_{t}^{i}$ for $i \in\{L, H\}$, and aggregate quantities $\left(\tilde{Y}_{t}, \tilde{K}_{t}, \tilde{L}_{t}, \tilde{X}_{t}^{p u b}, \tilde{X}_{t}, \tilde{C}_{t}, \tilde{I}_{t}\right)$ in periods $t=1, \ldots$ such that the following hold.

1. Aggregate variables are equal to the sum of individual variables:

$$
\begin{aligned}
& \tilde{X}_{t}=\phi x_{t}^{L}+(1-\phi) x_{t}^{H}, \\
& \tilde{C}_{t}=\phi c_{t}^{L}+(1-\phi) c_{t}^{H}+\frac{1}{1+n}\left[\phi \psi\left(h_{t-1}^{L}\right) d_{t}^{L}+(1-\phi) \psi\left(h_{t-1}^{H}\right) d_{t}^{H}\right], \\
& \tilde{L}_{t}=\phi e^{L} l_{t}^{L}+(1-\phi) e^{H} l_{t}^{H}, \\
& \tilde{X}_{t}^{p u b}=\eta_{t}\left(1+\frac{\phi \psi\left(h_{t-1}^{L}\right)+(1-\phi) \psi\left(h_{t-1}^{H}\right)}{1+n}\right) .
\end{aligned}
$$

2. Households maximize expected intertemporal lifetime utility, implying the first-order conditions (2.12).

3. Firms maximize profits, implying the first-order conditions (2.19).

4. The government runs a balanced budget (2.15).

5. The capital market is in equilibrium, implying

$$
(1+n) \tilde{K}_{t+1}=\left[\phi a_{t}^{L}+(1-\phi) a_{t}^{H}\right] .
$$

6. The dynamics of the aggregate capital stock are described by

$$
(1+n) \tilde{K}_{t+1}=\tilde{I}_{t}+(1-\delta) \tilde{K}_{t}
$$

7. The goods market equilibrium is depicted by

$$
\tilde{Y}_{t}=\tilde{C}_{t}+\tilde{G}_{t}+\tilde{X}_{t}^{p u b}+\tilde{X}_{t}+\tilde{I}_{t}
$$

In the following, we consider a steady state where stationary variables are constant. The conditions of the steady state are described in greater detail in Appendix A.1. 
Table 1

Calibrated parameters.

\begin{tabular}{llll}
\hline Description & Parameter & Value & Source/target \\
\hline Demographics and health & & & \\
Group size & $\phi$ & 0.5 & CPS data \\
Population growth & $n$ & 0.55 & United Nations (2015) \\
Elasticity of longevity & $\varepsilon$ & 0.20 & Hall and Jones (2007) \\
Scaling parameter for longevity & $\psi_{0}$ & 0.776 & life expectancy equal to 84.4 \\
Elasticity of health status & & & \\
w.r.t. private health spendings & $\gamma$ & 0.5 & Lichtenberg (2004) \\
Preferences & & & \\
Discount factor & $\beta$ & 0.3 & annual discount rate of $3.0 \%$ \\
Frisch elasticity of labor supply & $v_{1}$ & 0.25 & MaCurdy (1981), Altonij (1986) \\
Weight of labor & $v_{0}$ & 430 & average labor supply of 0.30 \\
& $b$ & 1.0 & aggregate targets (1)-(5) \\
Production & & & \\
Capital share & $\alpha$ & 0.3 & empirical capital share \\
Depreciation rate & $\delta$ & 1.00 & full depreciation \\
Productivity & $A$ & 20 & aggregate targets (1)-(5) \\
Skill premium & $\frac{e^{H}}{e^{L}}$ & 2.5 & BLS data \\
Government & $\theta_{1}$ & 0.137 & Brinca et al. (2016) \\
Tax progressivity & $\theta_{0}$ & 0.929 & average labor income tax of 28\% \\
Weight of income tax & $g_{H}$ & 0.06 & OECD data \\
Public health spending to GDP & $g_{C}$ & 0.15 & OECD data \\
Public consumption to GDP & & & \\
\hline
\end{tabular}

\section{Calibration}

We calibrate the model to match empirical characteristics of the US economy. Model periods correspond to 40 years in real life. Households start their working life at age 25 and retire at age 65. The maximum lifetime amounts to 104. Since we calibrate and analyze the model in steady state, the stationary variables are constant, so we can drop the period index $t$ in the following.

In our calibration strategy, we distinguish three sets of parameters: 1 ) parameters $\left(\phi, n, \varepsilon, \gamma, v_{1}, \alpha, \delta, e^{H}, e^{L}, \theta_{1}, g_{H}, g_{C}\right)$, which we can observe directly, such as the capital share $\alpha ; 2)$ parameters $\left(\psi_{0}, \beta, v_{0}, \theta_{0}\right)$, which we can calibrate to match one individual empirical observation, e.g., the utility parameter $v_{0}$, implying an average labor supply equal to 0.3 ; and 3 ) parameters $(A, b)$, which we choose jointly to match the following five empirical characteristics of the US economy as closely as possible: ${ }^{10}$

1. Annual real interest rate equal to $r-\delta=4 \%$,

2. Private consumption share in GDP equal to $(\tilde{C}+\tilde{X}) / \tilde{Y}=67 \%$,

3. Total health share in GDP equal to $\left(\tilde{X}+\tilde{X}^{p u b}\right) / \tilde{Y}=12 \%$,

4. Public to total health spending equal to $\tilde{X}^{p u b} /\left(\tilde{X}+\tilde{X}^{p u b}\right)=55 \%$,

5. Longevity education gap (difference in life expectancy of the skilled and unskilled) equal to 4.8 years.

In the following, we will describe the parameters related to demographics and health, preferences, production, and the government in turn. The calibrated parameters are listed in Table 1.

\subsection{Demographics and health}

We set the shares of the groups of skilled and unskilled households equal to 0.5, which is approximately equal to the average number of high school and college graduates during the period 1940-2019 as reported by the US Bureau of Labor Statistics. ${ }^{11}$ In accordance with United Nations (2015), we assume an average annual population growth rate of 1.1\%, implying a 40-year population growth rate $n=0.55$.

With respect to the calibration of the survival probability function (2.8), we set the elasticity of longevity with respect to health status equal to the average of the empirical estimates for age groups 20-65 reported by Hall and Jones (2007), $\varepsilon=0.20$. This value is also in accordance with the results of Baltagi et al. (2012), who report elasticities for males at age 65 ranging between 0.05 and 0.26. ${ }^{12}$ The scaling parameter $\psi_{0}$ is chosen to match the average life expectancy at the beginning of model period 2 (corresponding to real-life age 65) with the life expectancy at age 65 reported by National Center for Health Statistics (2018), which amounts to 84.4 years for the years 2012-2017.

\footnotetext{
10 The data on the real interest rate and longevity gap are taken from the World Bank and Pijoan-Mas and Ríos-Rull (2014), respectively, while the other empirical estimates are provided by the OECD.

11 We set the relative numbers equal to the mean for households with high school degrees and those with more schooling as the highest level of education during this period. The data are taken from the CPS Historical Time Series Tables, Table A-1: Years of School Completed by People 25 Years and Over, by Age and Sex: Selected Years 1940-2019.

12 Pestieau et al. (2008) use a slightly lower value of $\varepsilon=0.1$.
} 
Table 2

Calibration fit.

\begin{tabular}{llll}
\hline Description & Value & Target & Data source \\
\hline 1. Real interest rate p.a. $r-\delta$ & $4.2 \%$ & $4.0 \%$ & World Bank data \\
2. Private consumption share $\frac{C+X}{Y}$ & $72 \%$ & $67 \%$ & OECD data \\
3. Total health share to GDP & $8.3 \%$ & $12.0 \%$ & OECD data \\
4. Public to total health spending & $72 \%$ & $55 \%$ & OECD data \\
5. Longevity education gap & 2.77 yrs & 4.8 yrs & Pijoan-Mas and Ríos-Rull (2014) \\
\hline
\end{tabular}

The empirical evidence with respect to the parameter $\gamma$ of the health production function (2.6) is less clear-cut. There is vague evidence that the health production elasticity of public health expenditures, $1-\gamma$, is slightly higher than that of private expenditures, $\gamma$. Lichtenberg (2004) finds that public health expenditures have a higher marginal effect on longevity than private health expenditures. However, the difference is not statistically significant. Self and Grabowski (2003) find similar results for developed countries. Focusing on developing countries, Novignon et al., 2012 report a stronger correlation of health status with public health spending than with private health expenditure. Therefore, we use a benchmark value $\gamma=0.50$ but provide a sensitivity analysis for $\gamma \in[0.3,0.7]$ in Appendix A.4. ${ }^{13}$

\subsection{Preferences}

We choose $\beta=0.3$, which corresponds to an annual discount rate equal to $3 \%$. The Frisch elasticity of labor supply, $v_{1}=0.25$, is chosen from the middle range of empirical estimates. MaCurdy (1981) and Altonij (1986), for example, report Frisch elasticities of 0.23 and 0.28 , respectively. Moreover, we set $v_{0}$ such that the average labor supply equals 0.30 . The constant term $b$ in the utility function (2.13) is set equal to unity. As a consequence, we ensure that, in our model, a longer life is consistent with both a positive marginal utility from health expenditures and positive utility from consumption at any level.

\subsection{Production}

As we consider a period length equal to 40 years, we assume that capital depreciates fully, implying $\delta=1.0$. We set the capital share $\alpha=0.3$. The productivity parameter $A=20$ (together with the parameter $b$ ) is chosen to minimize the divergence of our model statistics from aggregate targets (1)-(5) above. We set the skill premium $\left(e^{H} / e^{L}\right)$ equal to 2.5 , as we find weekly hourly earnings of college graduates to be approximately 2.5 times higher than those of high school drop-outs. ${ }^{14}$

\subsection{Government}

We follow Brinca et al. (2016) and set the tax progressivity $\theta_{1}=0.137$ to replicate the average tax progressivity for US households. ${ }^{15}$ We calibrate $\theta_{0}$ such that the average labor tax rate is $28 \%$, as reported by Mendoza et al. (1994) and Trabandt and Uhlig, 2011. Finally, we assume that, in the benchmark case, public health expenditures and public consumption take fixed values relative to GDP described by $\tilde{X}_{t}^{\text {pub }}=g_{H} \tilde{Y}_{t}$ and $\tilde{G}_{t}=g_{C} \tilde{Y}_{t}$, respectively. We set the shares of public health expenditures and government consumption to GDP, $g_{H}$ and $g_{C}$, equal to their mean values between 1970 and 2018 amounting to $6 \%$ and $15 \%$, respectively.

\subsection{Aggregate targets}

In Table 2, we present the macroaggregates implied by the calibration of the benchmark case and compare them to our target values. In general, we are able to provide a close fit to our targets with some minor exceptions. 1) We are able to closely match our (annualized) real interest rate of $4.0 \%$ (third column). In our model, the value reported in the second column is equal to $4.2 \%$. 2 ) The share of private consumption in GDP in our model (72\%) is also in good accordance with the empirical value in the US economy (67\%). Our model slightly overstates the empirical value, as we count all health expenditures as consumption rather than, at least in part, investment expenditures. 3) The longevity gap of the two educational groups is lower in our model than empirically, 2.8 years versus 4.8 years. Therefore, we understate the longevity gap by approximately half. However, our model assumes that longevity depends only on income and education, whereas in reality, other sources also affect longevity, such as health behavior, marital status, or simply genes, as emphasized by Pijoan-Mas and Ríos-Rull (2014). Since we omit these other causes, we end up with a relatively

\footnotetext{
${ }^{13}$ For logarithmic utility, we must restrict the calibration of $\varepsilon$ and $\gamma$ to $1>(\varepsilon \gamma)$. Otherwise, consumption and health expenditures become luxury goods, as shown by Chakraborty and Das (2005) and Bhattacharya and Qiao (2007). Moreover, Bhattacharya and Qiao (2007) show that $1>(\varepsilon \gamma)$ provides a unique solution of the household's problem with logarithmic utility.

14 To construct the skill premium, we use data from the U.S. Bureau of Labor Statistics on median weekly earnings of those aged 25 years and older for workers with less than a high school diploma (LEU0252916700) on the one hand and those with a bachelor's degree or higher (LEU0252918500) on the other hand. The skill premium has remained relatively stable at approximately 2.5 since 1994 . However, we are aware of the increasing trend prior to 1994.

15 Heathcote et al. (2017) apply a slightly higher value of $\theta_{1}=0.18$ because they include capital income as part of taxable income.
} 
small longevity gap. 4) Our total health share is slightly below the target value (8.3\% versus $12.0 \%)$, whereas 5 ) the ratio of public to total health spending is above the mean value during $1970-2018$ (72\% versus $55 \%)$. However, note that our latter value of $72 \%$ is in close accordance with the values observed after the introduction of Obamacare in 2014. As a consequence of Obamacare, the ratio of public to total health expenditures rose from approximately 48\% (during 2009-2013) to approximately 84\% (during 2014-2018) according to the OECD.

\section{Results}

In this section, we present our steady-state results for a variation of the progressivity parameter $\theta_{1}$ of the labor income tax rate schedule. When progressivity $\theta_{1}$ increases, the government has to adjust the steady-state tax level $\theta_{0}$ to finance constant government expenditures on public consumption and health, $\tilde{G}$ and $\tilde{X}^{p u b}$. First, we examine the general equilibrium effects on the individual and aggregate variables before we study the optimal tax schedule for the two cases of endogenous and exogenous longevity.

\subsection{General equilibrium effects of tax progressivity}

Fig. 1 presents the behavior of the individual variables for a variation of the tax parameter $\theta_{1}$ over the interval [0,0.34]. From upper left to the lower right, the figure displays the steady-state values of the labor supply $l^{i}$, average tax rate, net income $\hat{y}^{i}$, savings $a^{i}$, private health expenditures $x^{i}$, and life expectancy in years, $40\left(1+\psi^{i}\right)$, for the unskilled with $i=L$ (solid red line), skilled with $i=H$ (broken blue line), and the average worker (dotted green line). $\psi^{i} \equiv \psi\left(h^{i}\right)$ denotes the steady-state survival probability of the household with productivity $e^{i}, i \in\{L, H\}$.

When the government increases tax progressivity $\theta_{1}$, all households decrease their individual labor supply, as displayed in the upper-left panel in Fig. 1. The labor supply of both the unskilled (solid red line) and the skilled (broken blue line) are downward sloping. As a consequence, the average labor supply (dotted green line) also falls. Note that the skilled provide a higher labor supply than the unskilled because the substitution effect of a higher hourly net wage rate, $\theta_{0}\left(e^{H} w\right)^{1-\theta_{1}} /\left(l^{H}\right)^{\theta_{1}}>\theta_{0}\left(e^{L} w\right)^{1-\theta_{1}} /\left(l^{L}\right)^{\theta_{1}}$, outweighs the income effect for our choice of the utility function. ${ }^{16}$

To balance its budget, the government has to adjust the tax level parameter $\theta_{0}$ in response to the change in the progressivity parameter $\theta_{1}$ and, hence, lower aggregate labor supply. In particular, $\theta_{0}$ increases with $\theta_{1}$ for our calibration. ${ }^{17}$ Therefore, as depicted in the upper-right panel of Fig. 1, average taxes increase (decrease) for the skilled (unskilled) worker, while the marginal tax rates increase for both types (not presented).

While the net income of the skilled, $\hat{y}^{H}$, unanimously falls with higher tax progressivity $\theta_{1}$, the net income of the unskilled, $\hat{y}^{L}$, increases with $\theta_{1}$ because the effect of lower average income taxes dominates the effect from lower labor supply. Consequently, (net) income inequality falls with higher tax progressivity $\theta_{1}$, as depicted in the middle-left panel of Fig. 1 . Since the households allocate their net income to consumption $c^{i}$ (not presented), savings $a^{i}$, and private health expenditures $x^{i}, i \in\{L, H\}$, all three budget components mirror the behavior of the respective net income of the unskilled and skilled workers. For example, private health expenditures $x^{i}$ increase for unskilled workers but decrease for skilled workers. Therefore, we find that the longevity gap declines from 3.3 years under proportional taxation (with $\theta_{1}=0$ ) to 2.5 years with tax progressivity $\theta_{1}=0.34$.

As the distortion of the labor supply increases with $\theta_{1}$, aggregate income and, hence, aggregate private health spending $\tilde{X}$ decline, so that the average life expectancy in the economy falls with higher $\theta_{1}$ (see the dotted green line in the lower-right panel of Fig. 1 ). ${ }^{18}$ Therefore, we conclude as our first main result that the decline in both the longevity gap and inequality comes at the expense of a lower average lifetime and lower average disposable income. Accordingly, the general equilibrium effect outweighs the partial equilibrium effect on longevity, where the latter derives from the concave nature of the health production function.

In order to gauge the general equilibrium effect of tax progressivity on expected longevity of the individuals, we compare the effects of a flat-rate rather than a progressive income tax on longevity in general and partial equilibrium. The results are presented in Table 3. In general equilibrium (GE), a switch from progressive to flat-rate income taxation results in a decline of the lifetime of the low-skilled by 0.15 years (from 83.07 to 82.92 years) and an increase of the lifetime of the high-skilled by 0.39 years (from 85.85 to 86.14 years) so that the longevity education gap increases by approximately half a year, from 2.8 to 3.3 years. In the case of partial equilibrium (PE), we keep all other aggregate variables constant except for $\theta_{1}$. In particular, the gross wage rate $w$, the real interest

\footnotetext{
${ }_{16}$ This property of our model is in accordance with empirical observations for the US economy. Blundell et al. (2018) find a significant difference in both male and female employment at the intensive margin across skill groups. According to their Fig. 4, for example, men aged 25-55 with college, high school, and no high school worked approximately 45, 43, and 41 hours per week on average during the period $1978-2007$.

17 In Appendix A.1, we present a graphical exposition of the behavior of additional variables in response to a change in $\theta_{1}$, including $\theta_{0}$. There, we show that $\theta_{0}$ has to increase so that the government budget balances. There are two effects on tax revenue from a higher $\theta_{1}$. First, skilled workers have to pay higher average taxes than unskilled workers. Since their income is higher than that of the unskilled, tax revenue increases. For this reason, $\theta_{0}$ can be increased. Second, in general equilibrium, aggregate capital will also fall, and thus total production $\tilde{Y}$ and, therefore, aggregate labor income, $(1-\alpha) \tilde{Y}$, declines even further. For this reason, $\theta_{0}$ needs to be decreased to keep tax revenue constant. The net effect of these two effects on $\theta_{0}$ is positive, and hence $\theta_{0}$ increases with $\theta_{1}$. To keep the exposition as concise as possible, we only present the most important variables in this section and refer the interested reader to the Appendix A.1.

${ }^{18}$ However, there is a counteracting subordinate general equilibrium effect on average life expectancy. If life expectancy falls, public health spending per capita $\eta$ increases (for a given $\tilde{X}^{\text {pub }}$ ). See also Fig. A.1 in Appendix A.1 for the response of $\eta$ to a change in $\theta_{1}$. Since this is a secondround effect, average life expectancy nevertheless falls with $\theta_{1}$.
} 


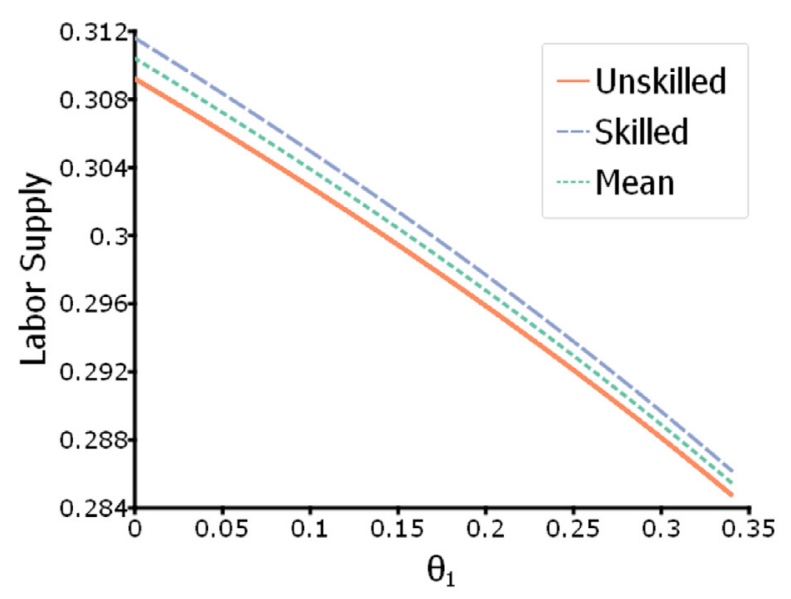

(a) Labor supply

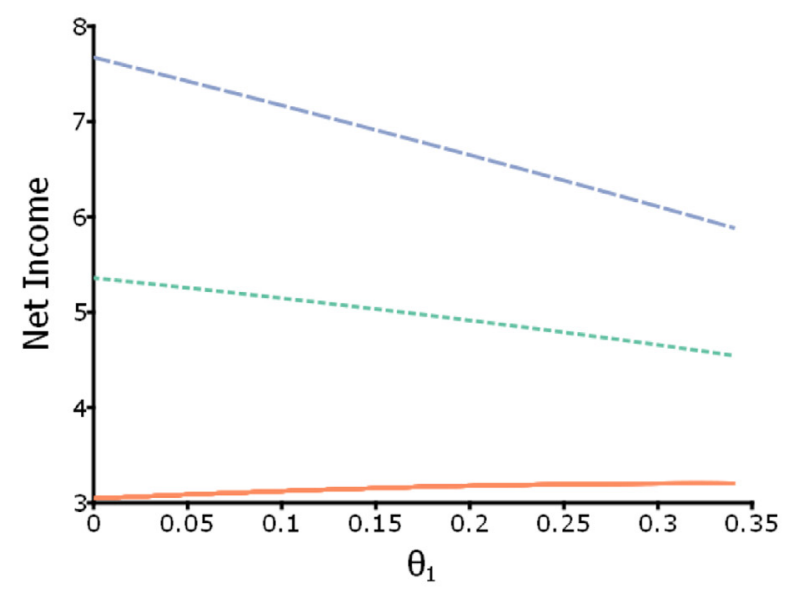

(c) Net Income

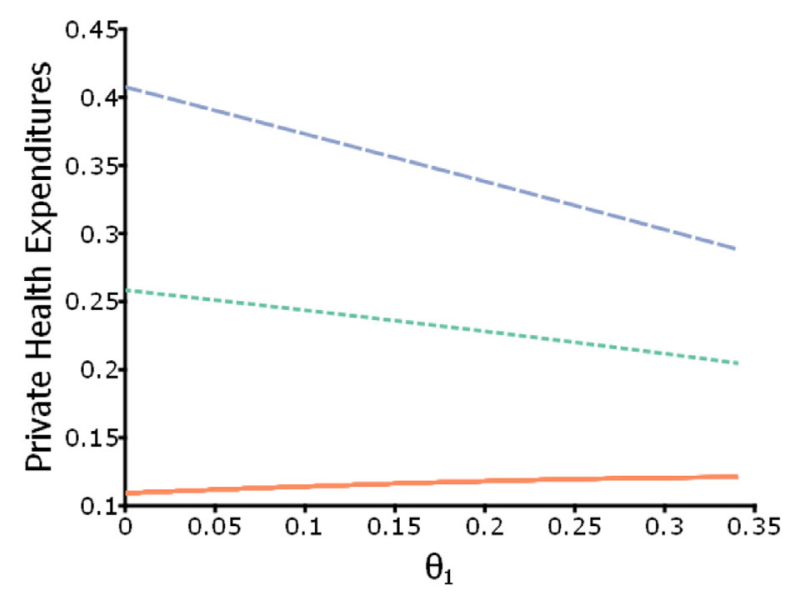

(e) Private health expenditures

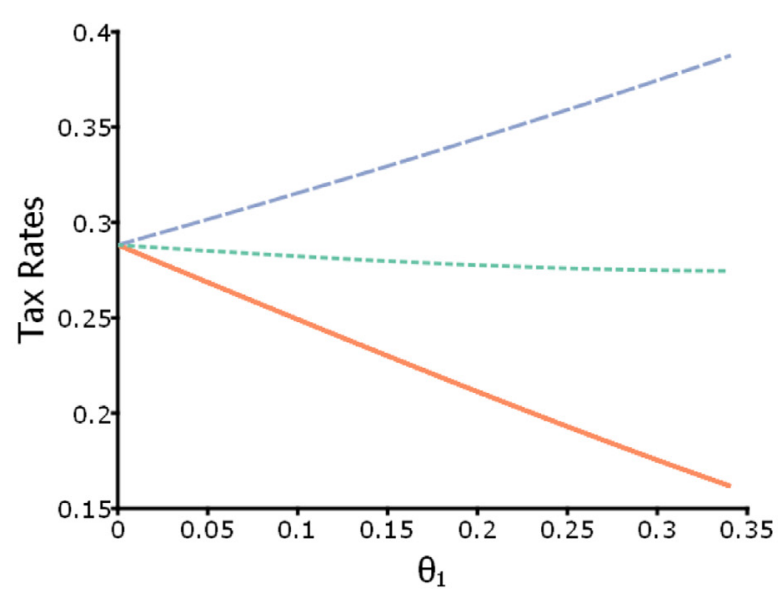

(b) Average tax rate

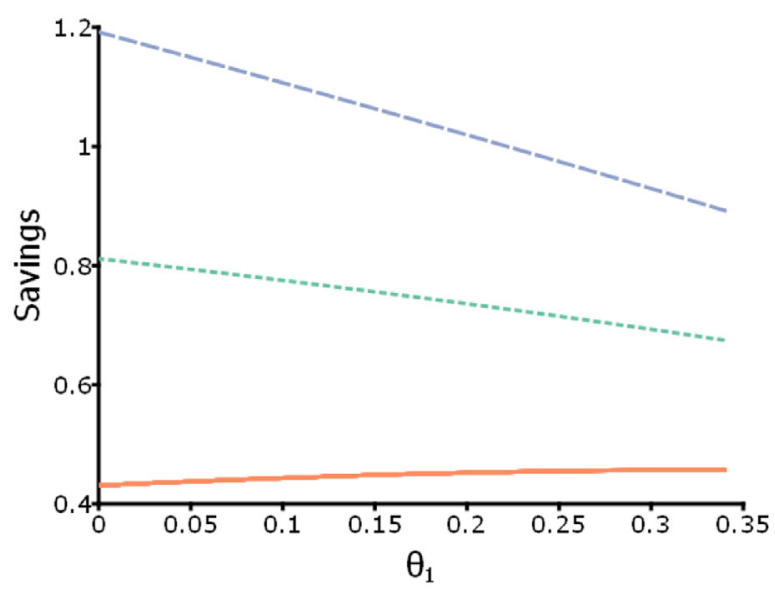

(d) Savings

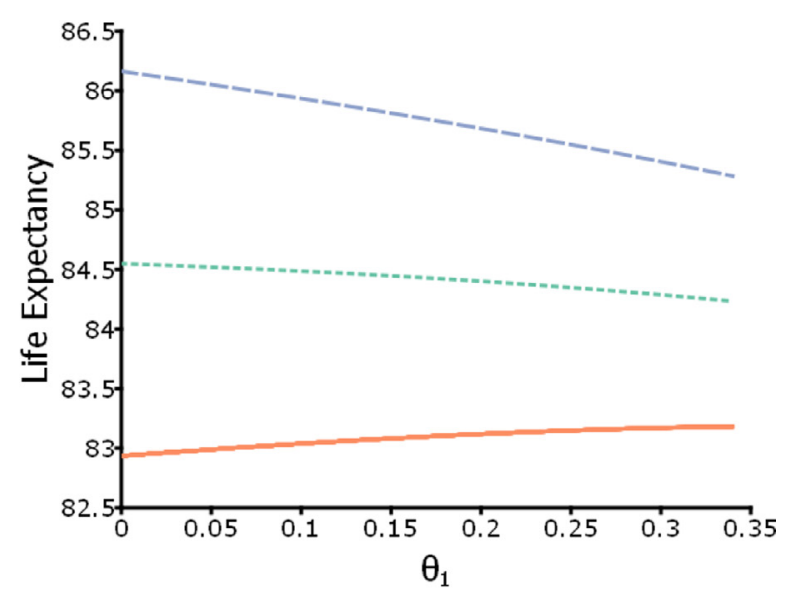

(f) Life expectancy

Fig. 1. Steady-state effects of tax progressivity $\theta_{1}$. 
Table 3

Tax progressivity $\theta_{1}$ and longevity.

\begin{tabular}{llll}
\hline & \multicolumn{2}{l}{ Longevity } & \\
\cline { 2 - 4 } Case & Low-skilled & High-skilled & Gap \\
\hline Benchmark & 83.07 & 85.85 & 2.77 \\
Flat tax, GE & 82.92 & 86.14 & 3.22 \\
Flat tax, PE & 83.84 & 87.12 & 3.27 \\
\hline
\end{tabular}

rate $r$, public health expenditures $\eta$ and the tax parameter $\theta_{0}$ are constant. Notice that in this case, the lifetime of the low-skilled even increases by 0.77 years and the increase in lifetime of the high-skilled is even stronger. In comparison of the GE and PE effects, we notice significant differences in the qualitative and quantitative response of the individual's longevity for the two types.

\subsection{Optimal income tax progressivity}

In this subsection, we study optimal tax progressivity for income-neutral tax reform. Therefore, we search for the optimal policy $\left(\theta_{0}, \theta_{1}\right)$ where we vary the progressivity $\theta_{1}$ and adjust $\theta_{0}$ such that the fiscal budget (2.15) remains balanced. Public expenditures on government consumption $\tilde{G}$ and health expenditures $\tilde{X}^{p u b}$ are kept constant at the benchmark level. We distinguish the two cases of endogenous lifetime, which is our benchmark model with endogenous individual health status $h^{i}, i \in\{L, H\}$, from Section 2 , and exogenous lifetime where we keep expenditures on private and public per capita health spending and, therefore, the survival probability $\psi^{i}, i \in\{L, H\}$, constant.

Welfare is measured by the average lifetime utility of newborns. ${ }^{19}$ Notice that we distinguish four different types of households, skilled and unskilled on the one hand and households that live one or two periods on the other hand. The four types are characterized by an endogenous distribution function over the four types, $\left(\phi \psi^{L}, \phi\left(1-\psi^{L}\right),(1-\phi) \psi^{H},(1-\phi)\left(1-\psi^{H}\right)\right)$. To compare different tax policies $\left(\theta_{0}, \theta_{1}\right)$, we compute the consumption equivalent change $(C E C)$ in comparison with the benchmark calibration $\theta_{1}=0.137$, i.e., the percentage change in total consumption that makes the average newborn under $\theta_{1}=0.137$ indifferent with respect to the allocation prevailing after a change to the new tax progressivity $\theta_{1}$.

\subsubsection{Endogenous longevity}

In the case of endogenous individual health expenditures $x^{i}$ and, hence, survival probability $\psi^{i}, i \in\{L, H\}$, we find that the optimal degree of progressivity amounts to $\theta_{1}^{*}=0.0642$, which is considerably lower than the present value in the United States, $\theta_{1}=0.137$. Due to the lower degree of progressivity, labor supply increases for both groups such that total production increases by $2.25 \%$ relative to the benchmark calibration. The labor income tax rate of unskilled workers increases from $23.50 \%$ to $26.31 \%$, while it decreases from $32.58 \%$ to $30.55 \%$ for skilled workers. As the drop in taxes from skilled workers is quantitatively larger than the increase in taxes from unskilled workers, the government has to increase average labor income taxes from $28.04 \%$ to $28.43 \%$ to balance the budget. Therefore, the net income of an unskilled worker, $\hat{y}^{L}$, decreases by $1.56 \%$, while that of a skilled worker, $\hat{y}^{H}$, increases by $5.34 \%$. Due to the lower tax progressivity, income inequality increases for both net and gross income. ${ }^{20}$ The Gini coefficients of net (gross) income increase from $0.197(0.249)$ to $0.212(0.252)$ in our model. ${ }^{21}$ With higher inequality of net income, unskilled households also decrease their private health expenditures relative to those of skilled workers, and hence the longevity gap increases from 2.77 years to 3.02 years. Table 4 summarizes our results.

Aggregate welfare increases by $0.19 \%$ of total consumption if tax progressivity decreases from $\theta_{1}=0.137$ to $\theta_{1}^{*}=0.0642$. The increase in aggregate welfare is caused by the general equilibrium effects, which overcompensate for the partial equilibrium effect on welfare from the redistribution of income from the poor (the unskilled) to the rich (the skilled). Per capita production $\tilde{Y}$ increases by $2.2 \%$, from 10.333 to 10.565 , and thus total consumption also increases. However, not all types of households benefit from tax policy $\theta_{1}^{*}$. The expected lifetime utility of unskilled households decreases by $3.22 \%$ of consumption, while it increases by $3.65 \%$ of consumption for skilled households. As a consequence, our optimality result depends crucially on the choice of the welfare function. The Rawlsian criterion, for example, would lead to a much higher optimal tax progressivity. ${ }^{22}$

In addition, we find that average longevity increases by a small amount, from 84.4 to 84.5 years, for the optimal tax progressivity parameter $\theta_{1}$. The increase in longevity of the high-skilled is larger in absolute value than the decrease in longevity of the lowskilled. The effect of a longer lifetime on welfare is not unanimous. On the one hand, a higher expected lifetime (particularly among the high-skilled) increases savings. In our model, steady-state welfare increases with a higher capital stock and, therefore, with higher longevity. ${ }^{23}$ On the other hand, the household does not consider the negative fiscal externality of his health expenditures.

\footnotetext{
${ }^{19}$ In Appendix A.3, we consider a decomposition analysis of ex post welfare effects for the individual types of households.

${ }^{20}$ We define income as the sum of labor and interest income.

${ }^{21}$ For the United States, Budría Rodríguez et al. (2002) find a Gini coefficient of gross income equal to 0.553. Our simple 2-period life-cycle model is unable to match the empirical Gini coefficient of income, as we do not consider age-dependent productivity, the skewness of the income distribution (in particular, the top percentile), or self-employment, among other factors.

22 In Appendix A.3, we demonstrate that the Rawlsian criterion implies an optimal tax progressivity parameter $\theta_{1}=0.4664$.

${ }^{23}$ Notice that, in the competitive equilibrium, the interest rate is calibrated above the population growth rate, $r>n$. As a consequence, the economy is not characterized by dynamic inefficiency. With increasing savings, the interest rate approaches the golden-rule level with $r=n$.
} 
Table 4

Optimal tax policies $\theta_{1}^{*}$ and steady-state allocation.

\begin{tabular}{|c|c|c|c|c|c|c|}
\hline \multirow[b]{2}{*}{$\theta_{1}$} & \multicolumn{2}{|c|}{ Benchmark } & \multicolumn{2}{|c|}{ Endogenous longevity } & \multicolumn{2}{|c|}{ Exogenous longevity } \\
\hline & \multicolumn{2}{|l|}{0.137} & \multicolumn{2}{|c|}{$\theta_{1}^{*}=0.0642$} & \multicolumn{2}{|c|}{$\theta_{1}^{*}=0.0806$} \\
\hline \multicolumn{7}{|c|}{ Aggregates and Averages } \\
\hline$\tilde{Y}$ & \multicolumn{2}{|c|}{10.333} & \multicolumn{2}{|c|}{10.565} & \multicolumn{2}{|c|}{10.503} \\
\hline Income tax rate & \multicolumn{2}{|c|}{$28.04 \%$} & \multicolumn{2}{|c|}{$28.43 \%$} & \multicolumn{2}{|c|}{$28.37 \%$} \\
\hline Longevity gap & \multirow{2}{*}{\multicolumn{2}{|c|}{$2.77 \mathrm{yrs}$}} & \multirow{2}{*}{\multicolumn{2}{|c|}{$\begin{array}{l}3.02 \mathrm{yrs} \\
+0.19 \%\end{array}$}} & \multirow{2}{*}{\multicolumn{2}{|c|}{$2.77 \mathrm{yrs}$}} \\
\hline$C E C^{a g g}$ & & & & & & \\
\hline \multicolumn{7}{|l|}{ Gini coefficients } \\
\hline Net income & \multicolumn{2}{|c|}{0.197} & \multicolumn{2}{|c|}{0.212} & \multicolumn{2}{|c|}{0.209} \\
\hline Gross income & \multicolumn{2}{|c|}{0.249} & \multicolumn{2}{|c|}{0.252} & \multicolumn{2}{|c|}{0.251} \\
\hline \multicolumn{7}{|c|}{ Individual variables } \\
\hline$i$ & $L$ & $H$ & $L$ & $H$ & $L$ & $H$ \\
\hline$\hat{y}^{i}$ & 3.147 & 6.979 & 3.098 & 7.352 & 3.108 & 7.257 \\
\hline$l^{i}$ & 0.300 & 0.302 & 0.305 & 0.307 & 0.304 & 0.306 \\
\hline$T\left(y^{i}\right) / y^{i}$ & $23.50 \%$ & $32.58 \%$ & $26.31 \%$ & $30.55 \%$ & $25.71 \%$ & $31.03 \%$ \\
\hline$C E C^{i}$ & & & $-3.22 \%$ & $+3.65 \%$ & $-2.59 \%$ & $+2.85 \%$ \\
\hline
\end{tabular}

With increasing longevity, the government has to spend a higher share of its exogenous public health expenditures $X^{p u b}$ on retirees. Therefore, the public per capita health expenditures $\eta$ fall with higher longevity resulting in a decline of welfare. In our calibration, the first effect dominates so that welfare increases with higher longevity.

At this point, we would like to emphasize that our assumption of a two-type parameterization of inequality is rather limiting and a dramatic simplification. Therefore, our quantitative results cannot be used to draw specific implications for the optimal progressivity of the US income tax system. Our coarse approximation of the income distribution (or rather ability distribution) does not precisely capture the shape of the income distribution. For example, Saez (2001) argues that the top tail is better described by a Pareto distribution than a lognormal distribution. He shows that the optimal marginal tax rate critically depends on the thickness of the long tail. ${ }^{24}$ Moreover, Mankiw et al. (2009) point out that it is difficult to derive the ability distribution from the empirical income distribution. This further increases the ambiguity to use economic theory for public policy advice.

\subsubsection{Exogenous longevity}

To isolate the impact of endogenous longevity, we study the model of Section 2 for comparison but under the assumption of exogenous longevity. For this reason, we keep private health expenditures $x^{i}$ and, hence, the survival probabilities $\psi^{i}$ constant at the benchmark level for both skill groups $i \in\{L, H\}$. We find that optimal tax progressivity $\theta_{1}^{*}$ amounts to 0.0806 in this case and, again, is much lower than the calibrated value $\theta_{1}=0.137$ in the benchmark case. In addition, we derive as our main result of this study that optimal progressivity with exogenous longevity is higher than in the case with endogenous longevity. The explanation for this observation is straightforward. Although higher progressivity in the case of endogenous longevity reduces the private health spending of the poor due to the reduced redistribution - the poor workers are characterized by a larger marginal product of health production with respect to private health spending due to the concavity of the health production function (2.16) - welfare nevertheless continues to increase for values of the progressivity parameter $\theta_{1}$ below 0.0806 because the general equilibrium effect of higher average income increases average private health expenditures and, therefore, aggregate welfare.

The equilibrium effects of higher income tax progressivity $\theta_{1}$ under exogenous longevity are similar to those under endogenous longevity and are presented in the two rightmost columns of Table 4. Due to a higher $\theta_{1}$, the individual labor supply of both skilled and unskilled workers increases such that per capita production $\tilde{Y}$ rises from 10.333 to 10.503 . The welfare effect of the optimal tax policy amounts to only $0.11 \%$ of total consumption and is smaller than in the case of endogenous longevity. Similarly, inequality as measured by the Gini coefficient of gross (and net) income increases, albeit by less than under endogenous longevity. Of course, since we assume exogenous longevity, the longevity gap remains unchanged at 2.77 years.

\subsection{Transition dynamics}

In the former analysis, we concentrated on the steady state effects of a change in the tax progressivity parameter $\theta_{1}$. In this section, we extent our analysis and also consider the welfare changes of the generations born during the transition from the benchmark equilibrium to the new steady state. ${ }^{25} \mathrm{Fig}$. 2 presents the transition dynamics of the variables $K_{t}, L_{t}$, $\theta_{0, t}$ and the ex-post average lifetime utilities of the newborn, the low-skilled and the high-skilled for a change of the tax progressivity parameter from $\theta_{1}=0.137$

\footnotetext{
${ }^{24}$ In order to derive his results, he builds upon the seminal (partial-equilibrium) analysis by Mirrless (1971)

${ }^{25}$ We would like to thank Jeffrey Clemens and an anonymous referee for suggesting this analysis to us.
} 
Table 5

Summary of admissible parameter ranges and assumptions .

\begin{tabular}{lll}
\hline Sensitivity & $\begin{array}{l}\text { Result } 1 \\
\theta_{1}^{*} \leq 0.137\end{array}$ & $\begin{array}{l}\text { Result } 2 \\
\theta_{1}^{*}(\psi(h))<\theta_{1}^{*}(\bar{\psi})\end{array}$ \\
\hline Parameter & & \\
\hline $\begin{array}{l}\text { Frisch labor supply elasticity } \\
\text { Survival probability elasticity }\end{array}$ & $v_{1} \geq 0.178$ & $v_{1} \geq 0.0936$ \\
$\begin{array}{l}\text { Health production elasticity } \\
\text { Substition elasticity health, } \sigma^{h}=1 /(1-\rho)\end{array}$ & $\begin{array}{l}\gamma \geq 0.05 \\
\rho \in[-3.2,0.3]\end{array}$ & $\begin{array}{l}\gamma \geq 0.140 \\
\rho \in[-3.2,0.3] \\
\text { Inequality } e^{H} / e^{L}\end{array}$ \\
$\begin{array}{l}\text { Model elements } \\
\text { Accidental bequests }\end{array}$ & $\begin{array}{l}e^{H} / e^{L} \leq 2.9 \\
\text { Tax deductability of } \\
\text { private health expenditures }\end{array}$ & robust \\
$\begin{array}{l}\text { Stochastic health (Section } 6): \\
\text { coinsurance rate } \vartheta\end{array}$ & robust & robust \\
\hline
\end{tabular}

to the optimal long-run equilibrium value $\theta_{1}^{*}=0.0642$. In our analysis, we assume that the policy change in period $t=1$ is unexpected and once-and-for-all. ${ }^{26}$ Convergence to the new steady state occurs after approximately 10 periods. ${ }^{27}$

To understand the dynamics of the lifetime utilities for the generations born in period $t=0,1, \ldots$, we need to account for the fact that the policy change in period $t=1$ is unexpected. Therefore, the aggregate capital stock $\tilde{K}_{1}$ (upper left panel in Fig. 2) is constant because it is determined by the savings of the young households in the previous period 0 . Since the marginal income tax rate declines at $t=1$, labor supply of both worker types increases and aggregate labor supply $\tilde{L}_{1}$ jumps by $0.2 \%$. For this reason, the marginal product of capital and hence the interest rate increases. For given savings, the old generation experiences an increase in old age consumption in period $t=1$. As a consequence, average lifetime utility of the households born in period 0 increases unanimously for all types of workers and the average newborn (please see the middle right and the two bottom panels in Fig. 2).

The change in the lifetime utility of the generations born in the next period $t=1$ (when the tax progressivity parameter declines) depends on the type of the household. Due to the lower progressivity, low-skilled workers experience a decline in net labor income, while the opposite holds for the high-skilled workers. As a consequence, the (average) lifetime utility of the former falls, while that of the latter rises. In the following periods $t=2, \ldots$, average lifetime utilities of all types increase with the rise in aggregate capital and, hence, income. However, we notice that the average lifetime utility of the low-skilled even undershoots its long-run value for the first 4-5 periods, while that of the high-skilled converges to its new steady state value from below. We, therefore, observe that the average newborn even experiences a lower welfare gain during the periods $\mathbf{2}-\mathbf{5}$ than in the long-run equilibrium. The same dynamic behavior can be observed for endogenous longevity of both household types which convergence to their new steady state values from below (not presented).

We interpret our results from the transitional dynamics of the lifetime utilities carefully as follows. We should be cautious to use our numeric conclusions from the steady-state results for concrete policy recommendations. Our results only imply that less progressive taxes may have important welfare implications depending on both the endogeneity of longevity and the implementation period of such a policy change. With respect to the dynamics of a policy change, we find that lower tax progression results in a significant intermediate decline in both longevity and lifetime utility of the low-skilled. The adverse welfare effects on the low-skilled could be dampened by a more gradual change in the tax code that is implemented over a longer time horizon.

\section{Sensitivity analysis}

In this section, we study the sensitivity of our two results: 1) the optimal progressivity of the income tax system in our simple model is below the present value in the US economy, and 2) the optimal progressivity is lower in the case of endogenous longevity than in the case of exogenous longevity. First, we analyze the sensitivity with respect to model parameters before we relax the model assumption of perfect annuity markets and introduce tax deductibility of private health spending. The effects of stochastic health and health in the utility function are considered in the next section where we explicitly study the role of health insurance. ${ }^{28}$ The sensitivity of our results with respects to these parameters and model elements are presented in Table 5.

To summarize, we find that our first result of an optimal tax progressivity $\theta_{1}^{*}$ (under Utilitarian welfare) below the present US level (0.137) is robust to all the parameters considered with one minor exception. Only higher inequality well in excess of that corresponding to the present US earnings inequality results in higher optimal tax progressivity. Our second result is found to be only

\footnotetext{
${ }^{26}$ For this reason, we do not present the expected lifetime of the newborn, but the average ex-post lifetime utility of the newborns. The two lifetime utilities differ in period 0 . Households decide upon their old-age consumption in period 0 expecting a lower real interest rate $r_{1}$ than the actual one in period 1 after the policy change. Therefore, they end up having a higher consumption in old age than expected.

${ }^{27}$ The computation of the transition dynamics as a solution to a two-point boundary value problem is described in the Appendix A.2 and uses the technique of reverse shooting presented in Chapter 9.2.2 of Heer and Maußner (2009).

${ }^{28}$ Additional sensitivity analysis on the effects of inequality as measured by the relative productivities of the low- and the high-skilled, $e^{H} / e^{L}$, is provided in the Appendix.
} 


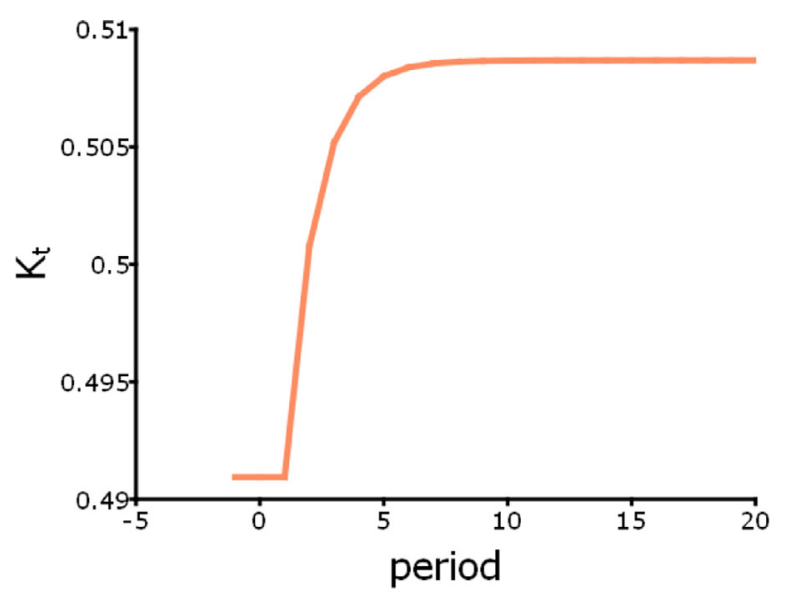

(a) Capital stock

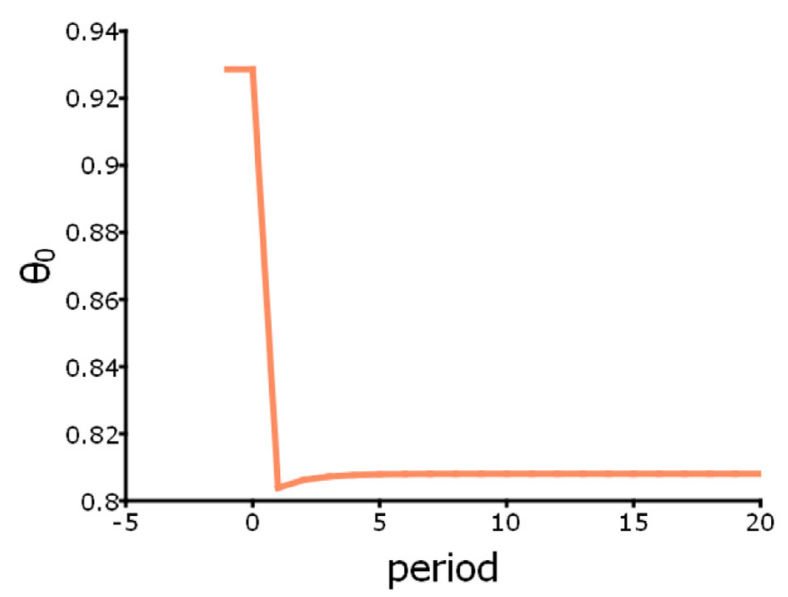

(c) $\theta_{0}$

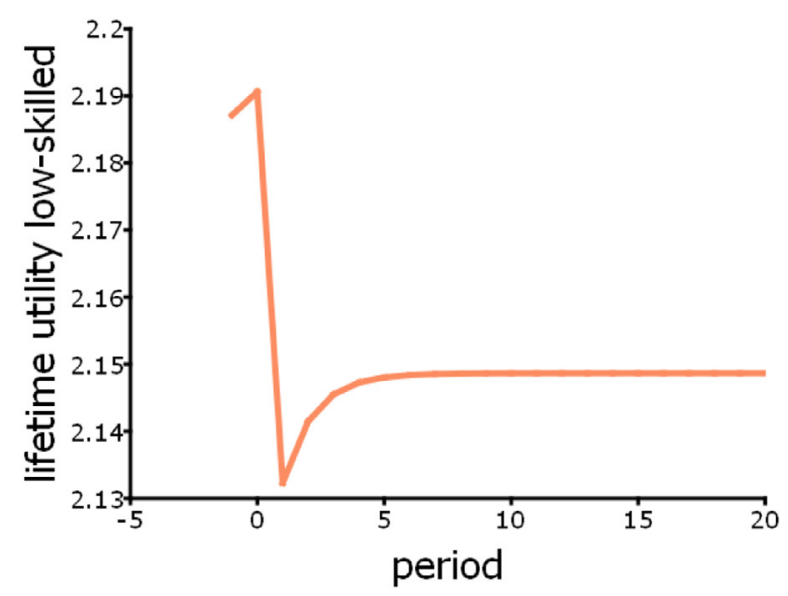

(e) Lifetime utility low-skilled

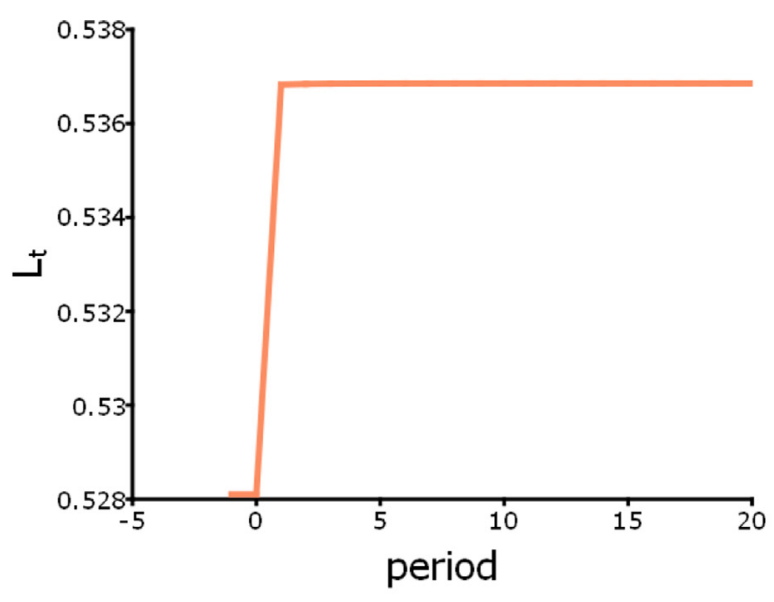

(b) Labor

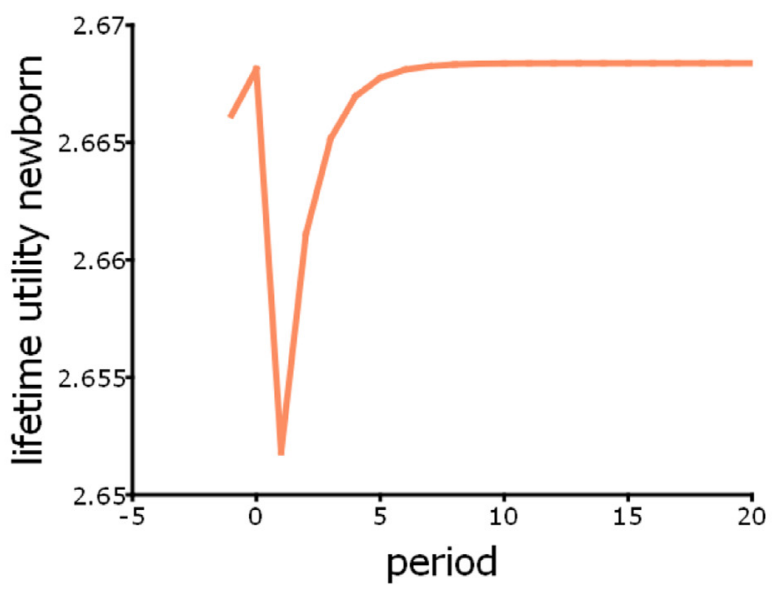

(d) Lifetime utility newborn

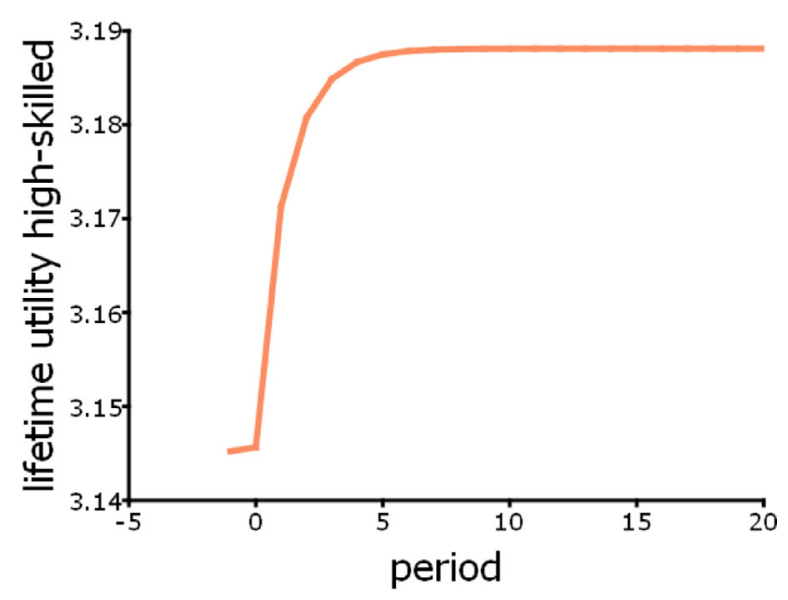

(f) Lifetime utility high-skilled

Fig. 2. Transition dynamics after a policy change from $\theta_{1}=0.137$ to $\theta_{1}^{*}=0.0642$. 
Table 6

Sensitivity analysis of optimal progressivity $\theta_{1}^{*}(C E C$

in percentage points in parentheses).

\begin{tabular}{lll}
\hline & Longevity & \\
\cline { 2 - 3 } & Endogenous & Exogenous \\
\hline Benchmark & 0.0642 & 0.0806 \\
& $(0.19)$ & $(0.11)$ \\
Model parameters & & \\
$v_{1}=0.3$ & 0.0294 & 0.0470 \\
& $(0.44)$ & $(0.31)$ \\
$\varepsilon=0.15$ & 0.0780 & 0.0806 \\
Model assumptions & $(0.12)$ & $(0.11)$ \\
Accidental bequests & 0.0543 & 0.0617 \\
& $(0.23)$ & $(0.19)$ \\
$x_{t}^{i}$ is tax deductible & 0.0318 & 0.0425 \\
& $(0.42)$ & $(0.31)$ \\
\hline
\end{tabular}

sensitive with respect to a small health production elasticity with respect to private health expenditures, $\gamma<0.354$. In addition, our two main results are robust to an extension of the model for 1) imperfect annuities market, 2) tax deductability of private health expenditures or 3) stochastic health and health in the utility. ${ }^{29}$

\subsection{Frisch elasticity of labor supply, $v_{1}$}

The tradeoff between higher income redistribution and tax distortions on welfare depends critically on the reaction of the individual labor supplies $l^{i}$ to higher marginal tax rates $\tau^{i}, \in\{L, H\}$, which is described by the Frisch elasticity of labor supply, $v_{1}$. In our benchmark calibration, we applied the value $v_{1}=0.25$. Estimates of $v_{1}$ implied by microeconometric studies vary considerably. MaCurdy (1981) and Altonij (1986) both use PSID data to estimate values of 0.23 and 0.28 , respectively, while Killingsworth (1983) finds a US labor supply elasticity equal to $v_{1}=0.4$. Domeij and Floden (2006) argue that these estimates are biased downward due to the omission of borrowing constraints. In macroeconomic studies such as Trabandt and Uhlig, 2011, a value of unity is often chosen to account for the effects of higher wages on labor along both the intensive and extensive margins.

The left-hand side of Fig. 3 describes the effect of $v_{1}$ on the optimal tax progressivity $\theta_{1}^{*}$ for different values of $\varepsilon \in\{0.2,0.1,0.25\}$, the elasticity of the survival probability with respect to health status. ${ }^{30}$ In the top-left panel of Fig. 3 , the benchmark value of $\varepsilon=0.20$ is depicted. Evidently, the optimal progressivity decreases with higher labor supply elasticity $v_{1}$. For empirically plausible values close to $v_{1}=0.40$, the optimal labor income tax rate is even found to be proportional with $\theta_{1}^{*}=0$. This result holds unanimously for the different values $\varepsilon \in\{0.2,0.1,0.25\}$.

For $v_{1}=0.30$, the optimal tax progressivity $\theta_{1}^{*}$ amounts to 0.0294 and 0.0470 in the cases of endogenous and exogenous lifetimes, respectively, as reported in Table 6 . Associated with these optimal progressivity values $\theta_{1}^{*}$, we find welfare gains in the amount of $0.44 \%$ and $0.31 \%$ of total consumption (see the number in parentheses below the entries for $\theta_{1}^{*}$ in Table 6 ), respectively.

In addition, we find that for a given $\varepsilon=0.20$, the break-even point between the optimal tax progressivity in the two cases of endogenous and exogenous longevity lies at $v_{1}=0.0936$, as shown in panel (a) of Fig. 3. Below this value of the Frisch labor supply elasticity, the effect that stems from the concavity of the health production function dominates the general equilibrium effect of higher average private health expenditures, and thus $\theta_{1}^{*}$ is higher with endogenous longevity. However, this value of $v_{1}$ is far below any empirically reported value for the Frisch elasticity. Therefore, our second result is also found to be robust to the empirically observed values of $v_{1}$.

\subsection{Longevity function, $\psi(h)$}

The channel of transmission from tax policy and redistribution to the equilibrium allocation and, hence, welfare also depends on the elasticity $\varepsilon$ of the survival probability $\psi(h)$ with respect to the health status $h$. The economic mechanism is as follows. A rise in progressivity $\theta_{1}$ decreases net income inequality ceteris paribus. As a consequence, unskilled (skilled) workers increase (decrease) their private health expenditures $x^{i}, i \in\{L, H\}$, such that health status $h^{i}$ increases (decreases) for unskilled (skilled) workers. With a higher elasticity $\varepsilon$, the longevity gap decreases to a larger extent. ${ }^{31}$ The effect on welfare, however, is not straightforward. On the

\footnotetext{
${ }^{29}$ For coinsurance rate of Medicare below $11 \%, \vartheta<0.11$, we find that moral hazard to take up excessive public health expenditure is sufficiently strong so that total government expenditures cannot be financed by a flat-rate income tax in our model any more. In this case, the top of the Laffer curve is associated with insufficient revenues for the financing of government revenues as studied in Heer et al. (2020).

${ }^{30}$ For each value of $v_{1}$, we recalibrated the model. In particular, $v_{0}$ was set to imply an equilibrium labor supply of 0.30 , among other changes. The goodness of fit is reported in Appendix A.4

${ }^{31}$ Again, we recalibrated our model for each value of the parameter $\varepsilon$. In particular, we adjusted $\psi_{0}$ to imply a life expectancy of 84.4 years at age 65 for the benchmark progressivity $\theta_{1}=0.137$.
} 


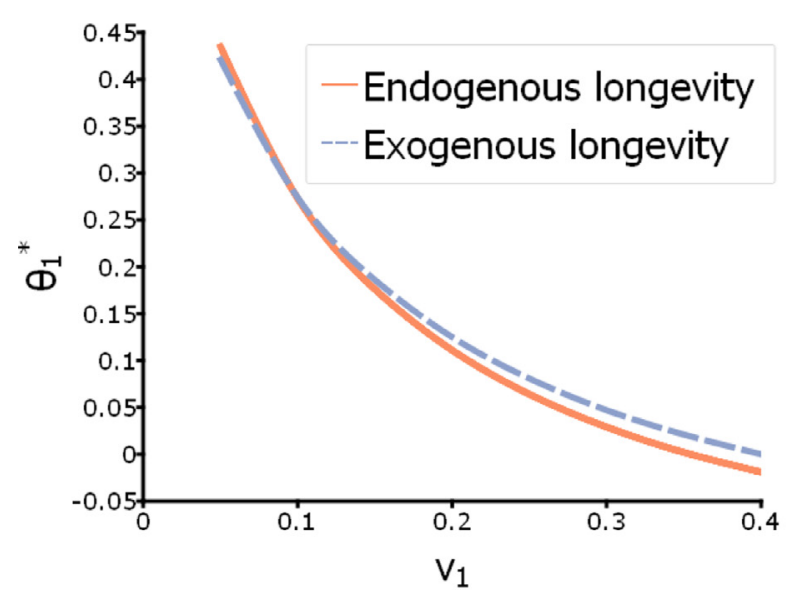

(a) Variation of $\nu_{1}$, given $\varepsilon=0.2$

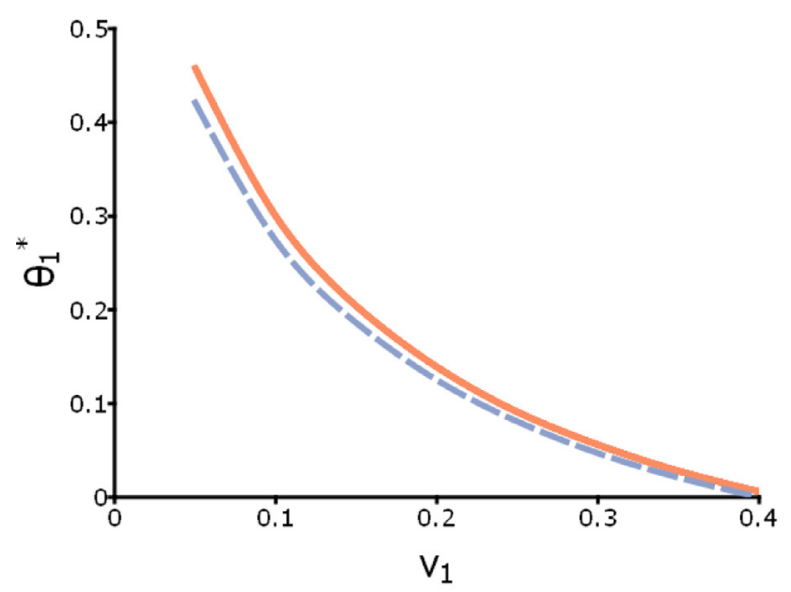

(c) Variation of $\nu_{1}$, given $\varepsilon=0.1$

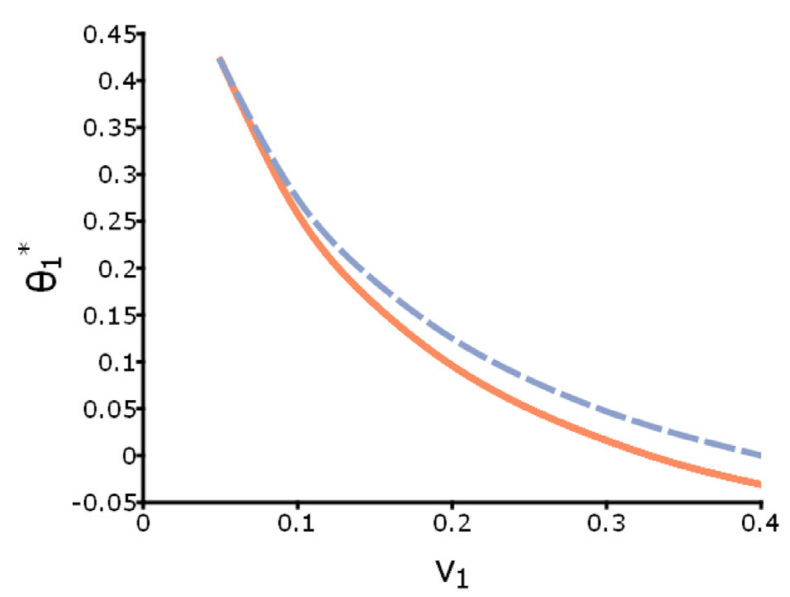

(e) Variation of $\nu_{1}$, given $\varepsilon=0.25$

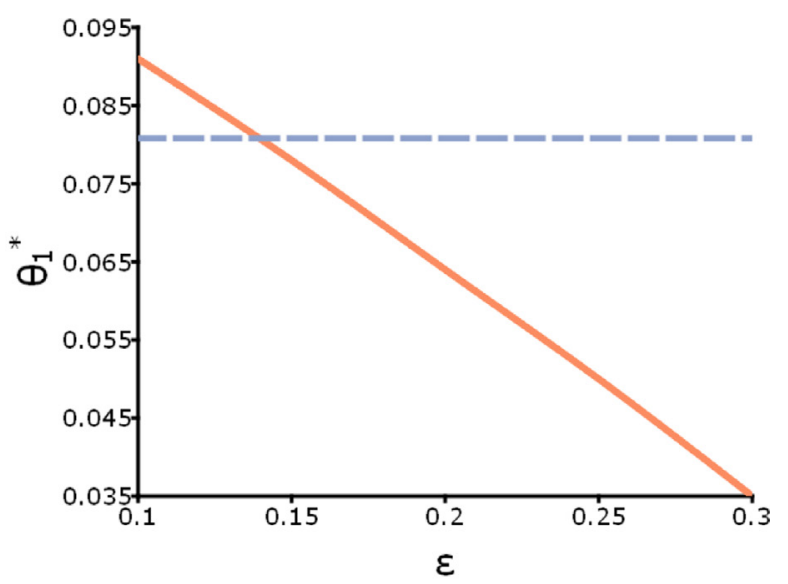

(b) Variation of $\varepsilon$, given $\nu_{1}=0.25$

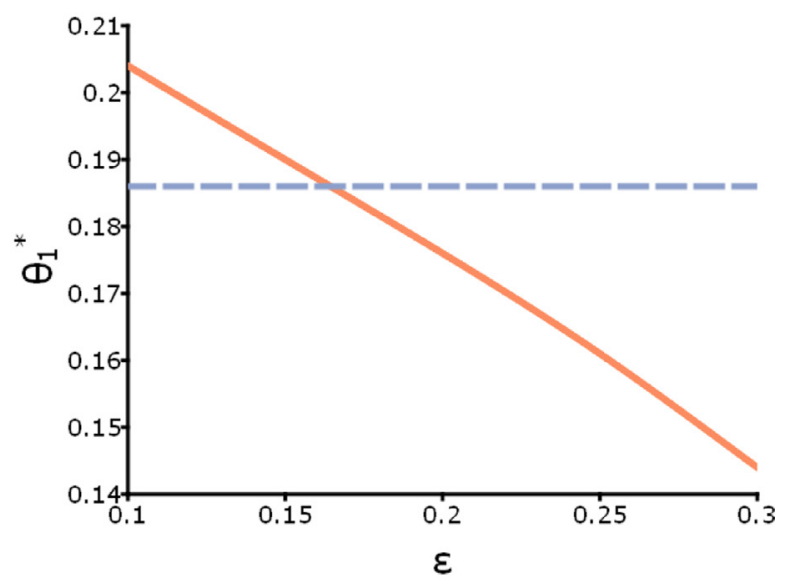

(d) Variation of $\varepsilon$, given $\nu_{1}=0.15$

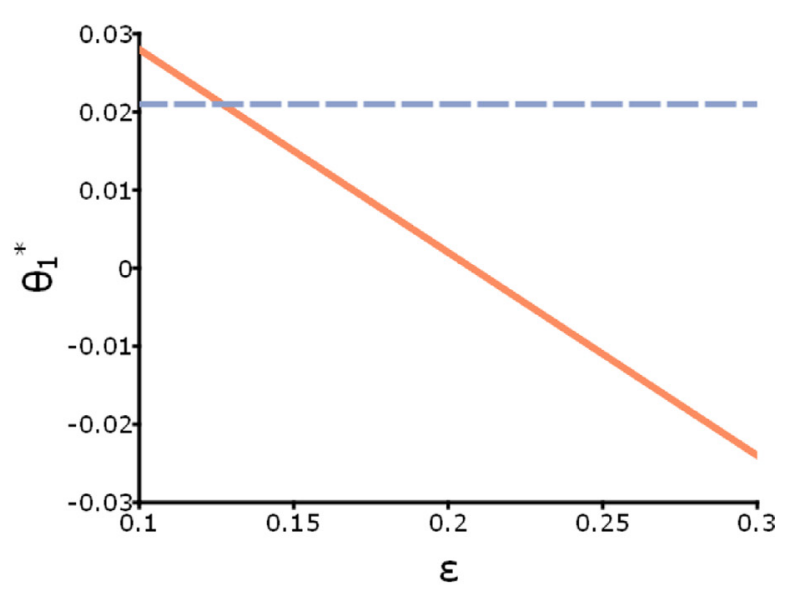

(f) Variation of $\varepsilon$, given $\nu_{1}=0.35$

Fig. 3. Sensitivity of optimal tax progressivity $\theta_{1}^{*}$ to variations of $v_{1}$ and $\varepsilon$. 


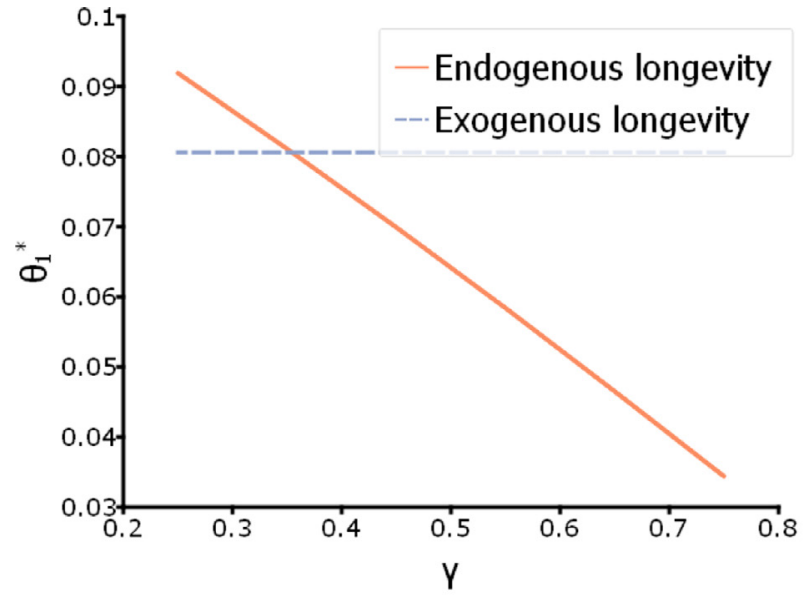

(a) Variation of $\gamma$

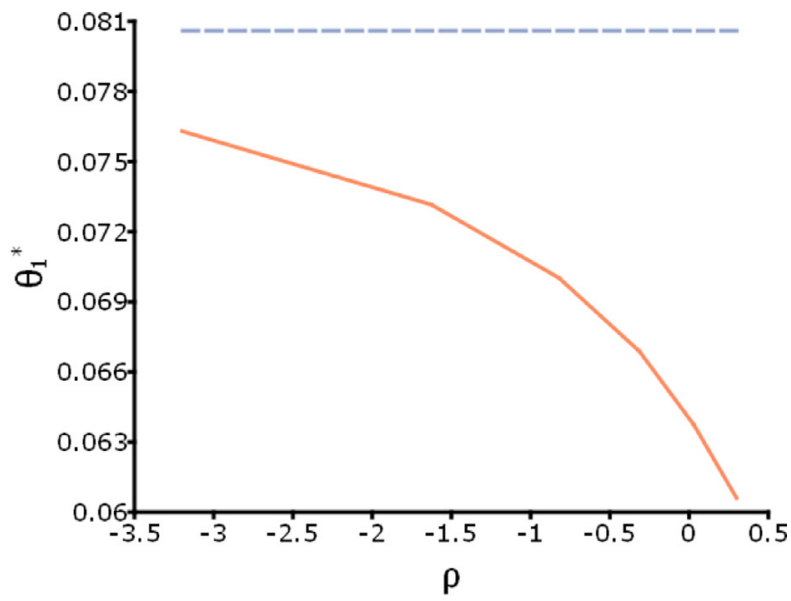

(b) Variation of $\rho$

Fig. 4. Sensitivity of optimal tax progressivity to $\gamma$ and $\rho$.

one hand, average lifetime increases because of the concavity of the longevity function $\psi(h)$, and therefore, aggregate lifetime utility increases (recall that we calibrated the utility parameter $b$ such that a longer lifetime also results in higher utility). On the other hand, the instantaneous utility of skilled workers in old age is higher than that of unskilled workers, as the former enjoy higher old-age consumption $d^{H}>d^{L}$. If higher income tax progressivity reduces the number of old-age workers with high utility relative to those with low utility, aggregate welfare decreases. In addition, we also observe general equilibrium effects that reinforce the negative effect of higher progressivity on welfare. If the expected lifetime of skilled (unskilled) workers decreases (increases), they reduce (increase) savings $a^{H}\left(a^{L}\right)$. Since the savings of the skilled are much larger than those of the unskilled, total savings and, hence, the capital stock decreases. As a consequence, total production and consumption also decline, which further depresses average lifetime utility.

We find that the negative welfare effects of higher income tax progressivity unanimously increase with elasticity $\varepsilon$. The top-right panel of Fig. 3 describes the effect of $\varepsilon$ on the optimal tax progressivity $\theta_{1}^{*}$ for the benchmark calibration with a Frisch labor supply elasticity $\nu_{1}=0.25$. For empirically reasonable values $\varepsilon \in[0.1,0.3], \theta_{1}^{*}$ decreases with increasing $\varepsilon$. Over the whole range of $\varepsilon$, optimal tax progressivity is considerably lower than the present value in the United States (amounting to 0.137). For $\varepsilon=0.15$, for example, the optimal tax progressivity amounts to $\theta_{1}^{*}=0.0780$ with a corresponding welfare gain of $0.12 \%$ of total consumption (see also Table 6). Of course, if we consider exogenous longevity, the optimal tax progressivity is constant at $\theta_{1}^{*}=0.0806$. For a given $v_{1}=0.25$, we find that endogenous longevity results in lower optimal progressivity (our second main result) as long as $\varepsilon \geq 0.1403$ holds.

In panels (d) and (f) of Fig. 3, we consider the effects of $\varepsilon$ on optimal progressivity $\theta_{1}^{*}$ for the Frisch labor supply elasticities 0.15 and 0.35 , respectively. The optimal progressivity $\theta_{1}^{*}$ continues to decrease with higher $\varepsilon$. For the low value $v_{1}=0.15$, we find that endogenous longevity implies lower optimal tax progressivity than exogenous longevity (our second result) if $\varepsilon \geq 0.1643$; if we set $v_{1}=0.35$, we find that this threshold decreases to $\varepsilon \geq 0.1269$. Thus, the higher $v_{1}$ is, the lower the threshold of $\varepsilon$ below which our second finding is reversed. We summarize the results of our sensitivity analysis with respect to the two parameters $v_{1}$ and $\varepsilon$ by the observations that our first main result continues to hold for empirically observed values of the Frisch labor supply elasticity, $v_{1} \geq 0.25$, and that our second main result continues to hold if longevity is sufficiently elastic with respect to health.

\subsection{Health production elasticity, $\gamma$}

In Section 3, we presented evidence from empirical studies that the production elasticities of health with respect to private and public health expenditures, $\gamma$ and $1-\gamma$, are not significantly different from each other, implying our calibration $\gamma=0.5$. To provide further robustness analysis, we check for the sensitivity of our results with respect to variation in the health production elasticity $\gamma$. The effects of a variation of $\gamma$ on $\theta_{1}^{*}$ are presented in the left panel of Fig. 4. Similar to the elasticity $\varepsilon$ of survival with respect to health, the health production elasticity $\gamma$ also governs the impact of private health expenditures $x$ on endogenous survival $\psi$. Therefore, changing $\gamma$ creates equivalent effects to those resulting from a change in $\varepsilon$. Evidently, the optimal progressivity $\theta_{1}^{*}$ decreases with $\gamma$. For higher $\gamma$, private health expenditures $x$ play a more significant role in increasing longevity. Consequently, higher tax progressivity results in a larger decline in the longevity gap and, for this reason - as argued above in the sensitivity analysis for $\varepsilon-$ optimal progressivity $\theta_{1}^{*}$ should be smaller due to general equilibrium effects. Note that both of our main results are robust to the choice of $\gamma$. First, the optimal progressivity $\theta_{1}^{*}$ is below the present US tax progressivity, $\theta_{1}=0.137$. Second, the optimal tax progressivity $\theta_{1}^{*}$ is lower under endogenous than under exogenous longevity as long as the elasticity of health with respect to private health expenditures, 
$\gamma$, exceeds the value 0.3538 . We can interpret our results in a way to think about how insurance impact on the results. ${ }^{32}$ The share of health expenditures that is provided by the worker can also be regarded as the private coinsurance rate of the public health system. Therefore, if the public health system fully insures the households (and $\gamma$ converges to zero), the optimal progressiveness of the income tax system increases and might also be higher than in the case of exogenous survival probability. ${ }^{33}$

\subsection{Substitution elasticity between private and public health expenditures}

Next, we consider the sensitivity of our results to the substitution elasticity of private and public health expenditures. Up to now we assumed that the substitution elasticity between private and public health expenditures, $x$ and $\eta$, is equal to unity, $\sigma^{h} \equiv 1 /(1-\rho)=1.0$. The empirical evidence regarding whether to regard private and public health expenditures as substitutes $(\rho>0)$ or complements $(\rho<0)$ is mixed though. Fiorini (2010) uses World Bank data from 1997 to 2005 to estimate that public and private health expenditures are substitutes. Using US data from between 1987 and 2002, Cutler and Gruber (1996a), Cutler and Gruber (1996b), and Gruber and Simon (2008) report that public health expenditures crowd out private health expenditures. Accordingly, we test the sensitivity of our results to the substitution elasticity of private and public health expenditures. Following Bhattacharya and Qiao (2007), we apply a CES health production function

$$
h_{t}^{i}=\left[\gamma\left(x_{t}^{i}\right)^{\rho}+(1-\gamma) \eta_{t}^{\rho}\right]^{\frac{1}{\rho}}
$$

Our health production function (2.6) presents the special case with $\rho=0$ (corresponding to a substitution elasticity equal to unity). We vary the parameter $\rho$ over a wide range $[-3.2,0.3]$ to test for sensitivity.

Our results are presented on the right panel of Fig. 4. The optimal $\theta_{1}$ decreases with higher substitutability between private and public health expenditures. With increasing $\rho$, individual private health expenditures $x_{t}^{i}, i \in\{L, H\}$ and, hence, health are more sensitive to the effects of income redistribution such that the longevity gap declines more strongly with higher tax progressivity. Therefore, we again observe that this effect necessitates a lower optimal tax progressivity (analogous to the cases of $\varepsilon$ and $\gamma$ above). Moreover, the optimal tax progressivity $\theta_{1}^{*}$ is smaller for endogenous than exogenous longevity. Hence, our results are also robust to the value of the substitution elasticity between private and public health expenditures.

\subsection{Specification of the model}

Finally, we conduct sensitivity analyses with respect to model assumptions. In particular, we refrain from assuming perfect annuity markets. Instead, we assume that households leave behind accidental bequests that are redistributed among all survivors of the same skill group $i \in\{L, H\} .{ }^{34}$ Additionally, we allow for tax deductibility of private health expenditures from total taxable income as specified in the US tax system (Heathcote et al., 2017). ${ }^{35}$ As apparent from Table 6, neither extension changes our main results that endogenous longevity reduces optimal tax progressivity and that income tax progressivity should be below the current US level in our model. In both cases, optimal progressivity is even lower and welfare effects are stronger than in the benchmark model (see Appendix A.4).

\section{Role of insurance effects}

In our benchmark model of Section 2, the public health system has a limited role for insurance and only insures against the risk of longevity similar to a public pay-as-you-go pension system. If the household survives until old age, the public health system pays for medical services in old age. In order to additionally model the role of the public health system to insure against health risk, ${ }^{36}$ we introduce stochastic health in the benchmark in a very simplified way. At the beginning of retirement, households are subject to a shock on their health capital. Medical expenditures in old age are partially insured as in the US Medicare program. ${ }^{37}$ In addition, we need to provide a motive for the retirees to demand health services in old age. Therefore, instantaneous utility in both periods is now augmented to include health as an additional argument.

Let the health state of the individual with productivity level $e^{i}$ in old age be denoted by $h_{t}^{i, o}$. Following Jung and Tran (2016), we assume that health capital depreciates at the rate $\delta^{h}$ and is subject to a health shock $\epsilon_{t}^{i, h}$ at the beginning of old age in period $t$ that depends on the skill type $i$. In addition, the household can buy medical services $x_{t}^{i, o}$ which are co-financed by the government so that

\footnotetext{
32 We would like to thank an anonymous referee to point this out to us.

${ }^{33}$ We also consider the case of coinsurance of public health services in Section 6 where we introduce stochastic health in old age together with Medicare (partially insured health expenditures in old age).

${ }^{34}$ Wolff and Gittleman, 2014 provide evidence that households with high income inherit considerably more than those with low income. The same difference appears when comparing skill levels. Therefore, we refrain from lump-sum distribution of bequests across all households.

35 The model descriptions are available in detail in Appendix A.4.

${ }^{36}$ We would like to thank an anonymous referee who suggested this analysis to us.

37 Appendix A.6 provides a simple example of a partial equilibrium model with stochastic health risk to exemplify the welfare effects of public health insurance. Public health insurance increases average lifetime utility by redistributing income from those with good health to those with bad health. In addition, progressive income taxation may also help to reinforce this welfare effect if the distortionary effect of higher taxes on labor supply is sufficiently small.
} 
Table 7

Optimal tax progressivity $\theta_{1}^{*}$ with stochastic

health .

\begin{tabular}{llll}
\hline Case & Medicare tax & Longevity & $\theta_{1}^{*}$ \\
\hline 1 & flat & endogenous & 0.000 \\
2 & flat & exogenous & 0.000 \\
3 & progressive & endogenous & 0.039 \\
4 & progressive & exogenous & 0.042 \\
\hline
\end{tabular}

the individual and government pay the shares $\vartheta$ and $1-\vartheta$, respectively. We identify $\vartheta$ with the coinsurance rate of $20 \%$ in the US Medicare program as applied by Jung and Tran (2016). Health capital $h_{t}^{i, o}$ accumulates according to ${ }^{38}$

$$
h_{t}^{i, o}=\left(1-\delta^{h}\right) h_{t-1}^{i}+\omega\left(x_{t}^{i, o}\right)^{\gamma} \eta_{t}^{1-\gamma}+\epsilon_{t}^{i, h} .
$$

Notice that the health production function in old age has the same functional form as the health production function (2.16) in young age, but will be subject to lower productivity $\omega<1.0$. The old household chooses the medical expenditures $x_{t}^{i, o}$ at the beginning of the period $t$ after the observation of the shock $\epsilon_{t}^{h, i}$.

In order to introduce a demand for health services $x_{t}^{i, o}$ in old age, we assume that instantaneous utility in young and old age is a function of health capital $h$ as well: ${ }^{39}$

$$
u(c, l, h)=b+\kappa \ln c+(1-\kappa) \ln h-v_{0} \frac{l^{1+\frac{1}{v_{1}}}}{1+\frac{1}{v_{1}}},
$$

where labor in old age is equal to zero, $l=0$, and $\kappa$ and $(1-\kappa)$ reflect the shares of consumption and health in utility.

Expected lifetime utility $U\left(c_{t}^{i}, d_{t+1}^{i}, l_{t}^{i}, h_{t}^{i}, h_{t+1}^{i, o}\right)$ of a young household with productivity level $e^{i}$ in period $t$ is presented by

$$
U\left(c_{t}^{i}, d_{t+1}^{i}, l_{t}^{i}, h_{t}^{i}, h_{t+1}^{i, o}\right)=u\left(c_{t}^{i}, l_{t}^{i}, h_{t}^{i}\right)+\beta \psi\left(h_{t}^{i}\right) \mathbb{E}_{t}\left\{u\left(d_{t+1}^{i}, 0, h_{t+1}^{i, o}\right)\right\} .
$$

When young, households also have to pay a proportional tax $\operatorname{tax}^{M e d}$ on gross income $y_{t}^{i}$ for Medicare ${ }^{40}$ so that the budget constraint of the young is presented by

$$
c_{t}^{i}+x_{t}^{i}+a_{t}^{i}=y_{t}^{i}-\operatorname{tax}_{t}^{M e d} y_{t}^{i} .
$$

In old age, the household has to pay part of the medical expenses, $\vartheta x_{t+1}^{i, o}$, out of the pocket so that her budget reads as

$$
d_{t+1}^{i}+\vartheta x_{t+1}^{i, o}=\frac{\left(1+r_{t+1}\right)}{\psi\left(h_{t}^{i}\right)} a_{t}^{i}
$$

The government budgets are balanced and are described in more detail in the Appendix A.5. ${ }^{41}$

We calibrate the model so that we are able to replicate the distribution of health capital in old age. ${ }^{42}$ The annual rate of health capital depreciation $\delta^{h}$ is set to $1.3 \%$ which is the midpoint of the interval considered by Jung and Tran (2016). We also set the productivity parameter $\omega$ so that public health expenditures in old age amount to $4.2 \%$ of GDP as in the US economy.

Table 7 summarizes our results with respect to the optimal tax progressivity $\theta_{1}^{*}$ in the case of stochastic health. We distinguish four cases. Longevity is either endogenous or exogenous. ${ }^{43}$ Furthermore, we assume that public Medicare expenditures are financed with either a flat-rate tax on wage income or with the help of the proceeds from the progressive income tax (as described in Section 2). In the case of endogenous longevity and a flat-rate Medicare tax, we find that optimal progressivity $\left(\theta_{1}^{*}=0.000\right)$ is at the lower limit of $\theta_{1} \geq 0$ and is even lower than in the case with deterministic health $\left(\theta_{1}^{*}=0.0642\right)$ or the current level in the US economy $\left(\theta_{1}=0.137\right)$. Accordingly, we observe that the optimal progressivity $\theta_{1}^{*}$ is sensitive with respect to the assumption of health risk. Health risk in old age results in a higher variation of ex-post lifetime utility. In this case, the general equilibrium effects of distortionary labor income taxes are amplified and lower progressivity is found to be optimal. If public Medicare expenditures are also financed by progressive income taxes (cases 3 and 4), optimum progressivity amounts to $\theta_{1}^{*}=0.039$ (endogenous longevity) and $\theta_{1}^{*}=0.042$ (exogenous longevity) and our first main result, that optimal tax progressivity is lower than the current US one, prevails again.

\footnotetext{
${ }^{38}$ In the specification, we follow Jung and Tran (2016). The deterministic part of health accumulation is based upon Grossman (1972) and the disturbance $\epsilon_{t}^{i}$ can be interpreted as a random depreciation rate as described in Grossman (2000).

${ }^{39}$ In slight abuse of our notation in the Section 2, $u($.$) now denotes instantaneous utility from consumption, labor and health, while it denoted$ instantaneous utility from consumption only in the main part of the paper.

40 Subsequently, we will also study progressive income taxation.

${ }^{41}$ We also delegate the derivation of the equilibrium conditions and the description of the calibration method to Appendix A.6.

${ }^{42}$ In old age, the health capital in the bottom three quartiles of the US health capital distribution diverge by $-5.9 \%,-27.8 \%$ and $-59.1 \%$ from the one of the top quartile. We would like to thank Juergen Jung and Chung Tran for the provision of their estimates which is based upon data from the Medical Expenditure Panel Survey (MEPS). We were able to match this distribution exactly by our choice of $\epsilon_{t}^{i}$.

${ }^{43}$ In the latter case, we assume that $h^{i}, i \in\{L, H\}$, is constant and equal to the values in the benchmark calibration.
} 
Moreover, our second main result is also confirmed. In the case of endogenous longevity, the degree of tax progressivity is unanimously lower than in the case of exogenous longevity. ${ }^{44}$

With respect to longevity, we find that the age gap increases even stronger after a switch to a flat-rate income tax than in the model of Section 2. A flat-rate income tax in case 1 with endogenous longevity and flat Medicare tax results in a longevity education gap of 3.46 years (compared to 3.22 years in the case of deterministic health in old age). With a switch from a progressive to a flat-rate income tax, high-skilled workers increase their labor supply and, hence, their precautionary savings for uncertain medical expenditures in old age to a larger extent. As a consequence, they also spend more on private health expenditures.

\section{Conclusion}

Income inequality is increasing in many industrialized countries, including the United States. Governments around the world are exploring different ways to redistribute income from rich to poor agents. Progressive income taxation is a natural candidate; other measures include better access to education and health by subsidizing tertiary education and fostering the public health system.

The optimal tax policy must address the tradeoff between the positive welfare effects from redistribution on the one hand and the negative welfare effects from tax distortions on labor supply and accompanying general equilibrium effects on the other hand. In this paper, we investigated the optimal tax progressivity for a revenue-neutral income tax reform under endogenous longevity. Our results should be viewed in the light of appropriate modesty. We rather emphasize the comparative statics of particular economic considerations than the absolute numeric values. In general, we find in our simple model that labor income taxes display a smaller degree of progressivity than the present US income tax. In addition, we show that endogenous longevity diminishes the optimal degree of tax progressivity. An extensive sensitivity analysis confirms the negative impact of endogenous longevity on optimal tax progressivity. However, optimal labor income taxes are found to be more progressive if wage inequality increases above the present level or if we depart from the use of the Utilitarian welfare function.

Regarding the relevance of our results for policy, we emphasize that we have neglected various aspects of the existing US health system and causes of inequality. Therefore, one should be careful to directly implement our results in policy recommendations. We would like to mention the following three extensions of our model in future research. First, we only consider a two-period model of the life cycle. A more extensive 80-period model based on the work by Auerbach and Kotlikoff (1987) that also includes a social security system implies a much more realistic description of the individual optimization problem and, hence, equilibrium savings and factor prices. Savings provide an essential means for the self-insurance of individuals against negative income and health shocks. Second, we assume income certainty, while stochastic income and the risk of unemployment are important motives for government to redistribute income between individuals. Third, households in our model are only heterogeneous with respect to individual productivity but not with respect to innate abilities. We also refrain from modeling the endogenous choice of education. Therefore, we do not answer the question of whether the government should redistribute with the help of public spending on health and/or education rather than with more progressive income taxes. We consider this question central to the study of optimal redistribution.

\section{Supplementary material}

Supplementary material associated with this article can be found, in the online version, at 10.1016/j.jhealeco.2021.102515.

\section{References}

Altonij, J.G., 1986. Intertemporal substitution in labor supply: evidence from micro data. J. Polit. Econ. 94, S176-S215 Auerbach, A.J., Kotlikoff, L., 1987. Dynamic Fiscal Policy. Cambridge University Press, New York.

Baltagi, B., Moscone, F., Tosetti, E., 2012. Medical technology and the production of health care. Empir. Econ. 42, 395-411.

Bhattacharya, J., Qiao, X., 2007. Public and private expenditures on health in a growth model. J. Econ. Dyn. Control 31 (8), $2519-2535$.

Blundell, R., Joyce, R., Norris Keiller, A., Ziliak, J.P., 2018. Income inequality and the labour market in Britain and the US. J. Public Econ. 162 (C), 48-62.

Brinca, P., Holter, H.A., Krusell, P., Malafry, L., 2016. Fiscal multipliers in the 21st century. J. Monet Econ. 77, 53-69.

Budría Rodríguez, S., Giménez, J.D., Quadrini, V., Rull, J.V.R., 2002. Updated facts on the U.S. distributions of earnings, income, and wealth. Feder. Reserve Bank Minneap. 2-35.

Chakraborty, S., 2004. Endogenous lifetime and economic growth. J. Econ. Theory 116 (1), 119-137.

Chakraborty, S., Das, M., 2005. Mortality, human capital and persistent inequality. J. Econ. Theory 10 (2), $159-192$.

Chetty, R., 2006. A new method of estimating risk aversion. Am. Econ. Rev. 96, 1821-1834.

Conesa, J.C., Krueger, D., 2006. On the optimal progressivity of the income tax code. J.. Monet. Econ. 53, 1425-1450.

Cremieux, P.-Y., Ouellette, P., Pilon, C., 1999. Health care spending as determinants of health outcomes. Health Econ. 8 (7), 627-639.

Cristia, J., 2009. Rising mortality and life expectancy differentials by lifetime earnings in the United States. J. Health Econ. 28 (5), $984-995$

Cutler, D., Gruber, J., 1996. Does public health insurance crowd out private insurance? Q. J. Econ. 111, 391-430.

Cutler, D., Gruber, J., 1996. The effects of medicaid expansions on public insurance. Am. Econ. Rev. 86, 378-383.

Dalgaard, C.-J., Strulik, H., 2014. Optimal aging and death: understanding the Preston curve. J. Eur. Econ. Assoc. 12 (3), $672-701$.

Domeij, D., Floden, M., 2006. The labor supply elasticity and borrowing constraints: why estimates are biased. Rev. Econ. Dyn. 9, $242-262$.

Fiorini, T., 2010. Optimal savings and health spending over the life cycle. Eur. J. Health Econ. 11 (4), 355-365.

Grossman, M., 1972. On the concept of health capital and the demand for health. J. Polit. Econ. 80 (2), 223-255.

Grossman, M., 2000. The human capital model. In: Culyer, A.J., Newhouse, J.P. (Eds.), Handbook of Health Economics. Elsevier, pp. 347-408.

Gruber, J., Simon, K., 2008. Crowd-out 10 years later: have recent public insurance expansions crowded out private health insurance? J. Health Econ. 27, 201-217. Hall, R., Jones, C., 2007. The value of life and the rise in health spending. Q. J. Econ. 122 (1), 39-72.

44 In fact, if we even allow for a regressive income tax, $\theta_{1}<0$, we find that the optimal progressivity rates amount to -0.057 and -0.062 in cases 1 and 2 so that our second main result also holds in this case. 
Heathcote, J., Storesletten, K., Violante, G.L., 2017. Optimal tax progressivity: an analytical framework. Q. J. Econ. 134, $1693-1754$.

Heer, B., Maußner, A., 2009. Dynamic General Equilibrium Modeling: Computational Methods and Applications, 2nd Springer, Heidelberg.

Heer, B., Polito, V., Wickens, M.R., 2020. Population aging, social security and fiscal limits. J. Econ. Dyn. Control 116.

Holter, H.A., Krueger, D., Stepanchuk, S., 2019. How does tax progressivity and household heterogeneity affect Laffer curves? Quant. Econom. 10 (4), 1317-1356.

Jeske, K., Kitao, S., 2009. U.S. tax policy and health insurance demand: can a regressive policy improve welfare? J. Monet. Econ. 56, $210-221$.

Jung, J., Tran, C., 2016. Market inefficiency, insurance mandate and welfare: U.S. health care reform 2010. Rev. Econ. Dyn. 20, 132-159.

Killingsworth, M.R., 1983. Labor Supply. Cambridge University Press, Cambridge, MA.

Krueger, D., Ludwig, A., 2016. On the optimal provision of social insurance: progressive taxation versus education subsidies in general equilibrium. J. Monet. Econ. 77.

Lantz, P., House, J., Lepkowski, J., Williams, D., Mero, R., Chen, J., 1998. Socioeconomic factors, health behaviors, and mortality. J. Am. Med. Assoc. 279, 1703-1708. Lichtenberg, F., 2004. Sources of U.S. longevity increase, 1960-2001. Q. Rev. Econ. Stat. 44 (3), 369-389.

MaCurdy, T.E., 1981. An empirical model of labor supply in a life-cycle setting. J. Polit. Econ. 89, 1059-1085.

Mankiw, N.G., Weinzierl, M., Yagan, D., 2009. Optimal taxation in theory and practice. J. Econ. Perspect. 23 (4), $147-174$.

Martin, S., Rice, N., Smith, P., 2008. Does health care spending improve health outcomes? Evidence from english programme budgeting data. J. Health Econ. 27 (4), $826-842$.

Mays, G., Smith, S., 2011. Evidence links increases in public health spending to declines in preventable deaths. Health Af.f 30 (8), $1584-1593$.

Mendoza, E.G., Razin, A., Tesar, L.L., 1994. Effective tax rates in macroeconomics: cross country estimates of tax rates on factor incomes and consumption. J. Monet. Econ. 34, 297-323.

Mirrless, J.A., 1971. An exploration in the theory of optimal income taxation. Rev. Econ. Stud. 38 (114), $175-208$.

National Center for Health Statistics, 2018. Health, United States, 2017: With Special Feature on Mortality. Hyattsville, Maryland..

Novignon, J., Olakojo, S., Nonvignon, J., 2012. The effects of public and private health care expenditure on health status in Sub-Saharan Africa: new evidence from panel data analysis. Health Econ. Rev. 2 (22).

Pestieau, P., Ponthiere, G., Sato, M., 2008. Longevity, health spending, and pay-as-you-go pensions. Public Finance Anal. 46 (1), 1-18.

Pijoan-Mas, J., Ríos-Rull, J.-V., 2014. Heterogeneity in expected longevity. Demography 51 (6), 2075-2102.

Rosen, S., 1988. The value of changes in life expectancy. J. Risk Uncertain. 1 (3), 285-304.

Saez, E., 2001. Using elasticities to derive optimal income tax rates. Rev. Econ. Stud. 68 (1), 205-229.

Self, S., Grabowski, R., 2003. How effective is public health expenditure in improving overall health? A crross-country analysis. Appl. Econ. 35 (7), $835-845$.

Sorlie, E.B., Keller, J., 1995. Us mortality by economic,demographic and social characteristics: the national longitudinal mortality study. Am. J. Public Health 85 (2). 994-956-278

Trabandt, M., Uhlig, H., 2011. The Laffer curve revisited. J. Monet. Econ. 58, 305-327.

United Nations, 2015. World Population Prospects: The 2015 Revision, Methodology of the United Nations Population Estimates and Projections. ESA/P/WP. 242

Ventura, G., 1999. Flat-rate tax reform: a quantitative exploration. J. Econ. Dyn. Control 23, 1425-1458.

Wolff, E., Gittleman, M., 2014. Inheritances and the distribution of wealth or whatever happened to the great inheritance boom? J. Econ. Inequal. 12 (4), 439-468. 